\title{
Optimal Exercise of Executive Stock Options and Implications for Firm Cost*
}

\author{
Jennifer N. Carpenter \\ Richard Stanton \\ Nancy Wallace \\ New York University \\ U.C. Berkeley \\ U.C. Berkeley
}

December 3, 2007

*Financial support from the Fisher Center for Real Estate and Urban Economics is gratefully acknowledged. For helpful comments and suggestions, we thank Peter Carr, Darrell Duffie, Steven Grenadier, Peter Lakner, Mark Lowenstein and seminar participants at Boston College, Laval University, MIT, NYU Courant Institute, Stanford University and the University of Vienna. We also thank Rik Sen for valuable research assistance. Please direct correspondence to carpenter@stern.nyu.edu, stanton@haas.berkeley.edu, and wallace@haas.berkeley.edu. 


\title{
Optimal Exercise of Executive Stock Options and Implications for Firm Cost
}

\begin{abstract}
Options have become a major component of corporate compensation. Their cost to firms depends on the exercise policies of executives who face hedging constraints. This paper analyzes the optimal policy and option cost for an executive with general concave utility. We show analytically how the policy and cost vary with risk aversion, wealth, and dividend, and when there exists a single stock price boundary. We also provide an example with a split continuation region, and numerical results on volatility and beta effects. Option value decreases with risk aversion, increases with wealth and hedging opportunities, but can actually decline with volatility.
\end{abstract}


Options have become a major component of corporate compensation, with Frydman and Saks (2007) finding that options represent over $40 \%$ of total compensation for the top three executives in a sample of large firms. While option compensation is widely believed to create valuable performance benefits, firms, investors, and regulators are also becoming concerned about its cost, since a better understanding of option cost can help firms decide how to use options most efficiently. Recent accounting regulation, requiring firms to recognize option expense after 2005, has also intensified the demand for better valuation methods. The difficulty is that the value of these options depends on the exercise policies of option holders who face hedging constraints, so the usual theory does not apply.

In the case of an ordinary call, the holder can sell the option at any time, so his goal is presumably to maximize the option's present value. The value-maximizing exercise policy in a Black-Scholes world has been researched extensively (see Merton (1973), Van Moerbeke (1976), Roll (1977), Geske (1979), Whaley (1981), Kim (1990)). It calls for exercising the option once the stock price rises above a critical level. This critical level is increasing in the riskless rate, the stock return volatility, and the time remaining to maturity, and it is decreasing in the dividend rate, with no early exercise if the dividend rate is zero. By contrast, the holder of an executive stock option must bear the risk of the option payoff, so simply maximizing the option's present value is generally not optimal. Indeed, evidence indicates that executives systematically exercise options on non-dividend paying stocks well before expiration (see, for example, Bettis, Bizjak, and Lemmon (2005)). The executive presumably chooses an option exercise policy as part of a greater utility maximization problem that includes other decisions, such as portfolio and consumption choice and managerial strategy.

This paper conducts a comprehensive study of the optimal exercise policy for an executive stock option and its implications for option cost and related valuation concepts. Our paper is the first to provide analytical results for an executive with general concave utility. Working in a continuous-time framework, we give conditions under which the exercise policy is completely characterized by a single stock price boundary. We also present an example with a split continuation region, in which the executive exercises only at intermediate stock prices, but not at high or low prices. We give conditions under which the executive exercises later, and the option cost is greater, the lower his risk aversion and the greater his outside wealth. He exercises earlier with a higher dividend. On the other hand, exercise policy is not monotonic in stock return volatility, and option cost to shareholders can actually decline as volatility rises. 
When optimal trading of outside wealth in the market is possible, our numerical examples with constant relative risk averse utility suggest that, in the absence of constraints on the outside portfolio weight in the market, the exercise boundary and option value increase with the magnitude of the correlation between the stock return and the market return, independent of the sign of the correlation, approaching their levels under the value-maximizing policy. Imposing a bound on the magnitude of the market weight in the outside portfolio reduces boundaries and option values, and when the market risk premium is nonzero, the magnitude of the effect of the portfolio constraint depends on the sign of the correlation. When the market risk premium and stock beta are both nonnegative, increasing the stock beta increases option value.

We also compare our model's option costs with approximate values calculated using the method accepted by the Financial Accounting Standards Boards (FASB) and used by the vast majority of firms. We show how the approximation error varies with the stock beta, volatility, and dividend rate, and find that the error can be large or small, positive or negative. Moreover, in some cases the response of the FASB approximation to a change in parameters can actually be in the opposite direction to the true movement.

Finally, we examine subjective option value from the viewpoint of the executive and provide a general condition under which the option's subjective value is bounded above by the present value. Our examples show how the subjective discount varies with firm characteristics. The magnitude of the subjective discount suggests that the incentive benefits of option compensation must be large to offset its cost relative to cash compensation.

Overall, our analysis underscores the importance of accurately characterizing the exercise policy for option valuation. As more data on exercises become available, it will be possible to estimate an empirical option exercise and cancellation rate function and thus deduce option cost empirically. The results of this paper yield testable predictions about option exercise behavior and provide guidance about how to specify and interpret models for estimating option exercise rates and option cost.

\section{Related Literature}

The intuition that the need for diversification can lead an executive to sacrifice some option value by exercising it early is well understood in the literature, but explicit theory of the optimal exercise of ESOs is still developing. Huddart (1994), Marcus and Kulatilaka (1994), and Carpenter (1998) build binomial models of the utility-maximizing 
exercise decision with exogenous assumptions about how non-option wealth is invested. Detemple and Sundaresan (1999) extend these to allow for simultaneous option exercise and portfolio choice decisions. These papers establish the economic approach to ESO valuation, focusing on the optimality of early exercise (and the fact that this makes ESOs worth less than their Black-Scholes value), rather than an in-depth analysis of the exercise policy itself.

More recently, several papers have solved versions of the problem we describe here for the case of constant absolute risk averse utility, where the optimal exercise policy is independent of the executive's wealth. Leung and Sircar (2007) solve the finite horizon problem, and include the risk of job termination and the possibility of partial option exercise. Kadam, Lakner, and Srinivasan (2003) model the optimal exercise policy for an infinite horizon option, but the model links the manager's consumption date to the option exercise date, which can distort the exercise decision, even in the absence of trading restrictions. Henderson (2004) also models the optimal exercise policy for an infinite horizon real option and links the manager's consumption date to the option exercise date, but uses a specialized utility function so that this link does not distort the exercise policy. Ingersoll (2006) approximates option values assuming an optimal constant barrier policy and constant relative risk aversion. Other papers use specific utility functions to study the optimal partial exercise of options. These include Jain and Subramanian (2004), Henderson (2006), Grasselli (2006), and Rogers and Scheinkman (2007).

A number of papers model option value using exogenous specifications of the exercise policy. Jennergren and Näslund (1993), Carr and Linetsky (2000), and Cvitanić, Wiener, and Zapatero (2004) derive analytic formulas for option value assuming exogenously specified exercise boundaries and forfeiture rates. Hull and White (2004) propose a binomial model in which exercise occurs when the stock price reaches an exogenously specified multiple of the stock price and forfeiture occurs at an exogenous rate. Rubinstein (1995) and Cuny and Jorion (1995) also compute option value under exogenous assumptions about the timing of exercise.

Other authors have focused on the executive's private valuation of the option. These include Lambert, Larcker, and Verrecchia (1991), Hall and Murphy (2002), Cai and Vijh (2005), and Miao and Wang (2005). In addition, Ingersoll (2006) develops an analytic subjective option valuation methodology assuming the option is a marginal component of the executive's portfolio and the executive holds a fixed proportion of wealth in restricted stock. 


\section{General Framework}

Executive stock options are nontransferable and Section 16-c of the Securities Exchange Act prohibits corporate insiders from taking short positions in their company's stock. The use of zero-cost collars and equity swaps by corporate insiders documented by Bettis, Bizjak, and Lemmon (2001) suggests that insiders may have some scope for hedging their incentive compensation. However, evidence that the vast majority of options are exercised well before expiration, even when no dividend is present, suggests that option holders still face significant hedging constraints. This section lays out a general model of the executive's optimal exercise problem in the presence of hedging restrictions and defines the resulting option cost to shareholders.

\section{A. The Executive's Option Exercise and Portfolio Choice Problem}

The executive has $n$ finite-lived nontransferable options with strike price $K$ and expiration date $T$ and additional wealth $W$ that can be invested subject to a prohibition on short sales of the stock. The investment set includes riskless bonds with constant riskless rate $r$, the underlying stock with price $S_{t}$, and a market portfolio with price $M_{t}$. These prices satisfy

$$
\begin{aligned}
\frac{d S_{t}}{S_{t}} & =(\lambda-\delta) d t+\sigma d B_{t} \\
\frac{d M_{t}}{M_{t}} & =\mu d t+\sigma_{m} d Z_{t},
\end{aligned}
$$

where $B$ and $Z$ are standard Brownian motions with instantaneous correlation $\rho$ defined on a complete probability space equipped with the natural filtration. The stock return volatility, $\sigma$, the stock dividend rate $\delta$, and the mean and volatility of the market return, $\mu$ and $\sigma_{m}$ are constant. The mean stock return $\lambda$ is equal to the normal return for the stock given its correlation with the market,

$$
\lambda=r+\beta(\mu-r)
$$

where the $\beta=\rho \sigma / \sigma_{m}$. In particular, in the absence of the option, an optimal portfolio would contain no stock position beyond what is implicitly included in the market portfolio.

The executive simultaneously chooses an option exercise time $\tau$, which is a stopping time of the filtration generated by the Brownian motion, and an outside wealth investment 
strategy in the market and the stock, $\pi_{t} \equiv\left(\pi_{t}^{m}, \pi_{t}^{s}\right)$, satisfying $\mathrm{E} \int_{t=0}^{T}\left\|\pi_{t}\right\|^{2} d t<\infty$. His goal is to maximize the expected utility of time $T$ wealth, or equivalently:

$$
\max _{\left\{\tau \leq T, \pi^{m}, \pi^{s} \geq 0\right\}} \mathrm{E}\left\{V\left(W_{\tau}^{\pi}+n\left(S_{\tau}-K\right)^{+}, \tau\right)\right\}
$$

where $W^{\pi}$ denotes the outside wealth process under trading strategy $\pi$, given by

$$
d W_{t}^{\pi}=r W_{t}^{\pi} d t+\pi_{t}^{m}\left((\mu-r) d t+\sigma_{m} d Z_{t}\right)+\pi_{t}^{s}\left((\lambda-r) d t+\sigma d B_{t}\right)
$$

$V$ is the indirect utility of freely investable wealth,

$$
V\left(W_{t}, t\right) \equiv \max _{\pi^{m}} \mathrm{E}_{t}\left\{U\left(W_{T}\right)\right\} \text { s.t. } d W_{u}=r W_{u} d u+\pi_{u}^{m}\left((\mu-r) d u+\sigma_{m} d Z_{u}\right)
$$

and the utility function $U$ is strictly increasing, strictly concave, and twice continuously differentiable. Intuition suggests that the optimal outside position in the stock in problem (4) is $\pi^{s} \equiv 0$, however this remains to be proved.

This formulation entails a number of simplifications. The executive's portfolio does not include a position in restricted shares of stock (see Kaul, Liu, and Longstaff (2003) and Ingersoll (2006) for models of portfolio choice with restricted stock). It allows only for a single block exercise of the option, although the executive would probably prefer to exercise the options at a stochastic rate over time. The model also considers only a single grant of options when in practice, executives are granted new ten-year options every year and typically build up large inventories of options with different strikes and expiration dates. It would be useful to understand which options are most attractive to exercise first and how the anticipation of future grants of options and other forms of compensation affects current exercise decisions. In addition, the model does not account for any control the executive has over the underlying stock price process through the exertion of effort and through project and leverage choices; these choices may interact with the exercise decision. Despite these simplifications, we believe this formulation captures the essence of the executive stock option problem.

\section{B. Option Cost to Shareholders}

The solution to the executive's optimal exercise problem, that is, the optimal exercise policy $\tau$, defines the option payoff, $\left(S_{\tau}-K\right)^{+}$that occurs at time $\tau$. The cost of the option 
to shareholders who can trade freely is the present value, or replication cost, of that payoff. This can be represented as the risk-neutral expectation of the risklessly discounted option payoff,

$$
P=\mathrm{E}^{*}\left\{e^{-r \tau}\left(S_{\tau}-K\right)^{+}\right\}
$$

where $\mathrm{E}^{*}$ means the expectation is taken with respect to the probability measure under which the expected returns on both the market and the stock are equal to the riskless rate.

Standard theory for tradeable options assumes the option holder chooses the exercise policy to maximize the option's present value, because when the option is tradeable, maximizing present value is consistent with maximizing expected utility. When the option is nontransferable these objectives are different, and the utility-maximizing payoff typically has a lower present value.

In addition, when the option is nontransferable, its present value or cost to shareholders is different from its value to the executive. The value to the executive is the amount of freely investable cash that would make the executive as happy as having the nontransferable option. Section VI proves that this must be less than the option cost to shareholders and provides some examples. The discount in the executive's valuation of the option relative to its cost to shareholders is part of the price shareholders pay for improved performance benefits relative to cash compensation.

\section{Exercise Policy and the Effect of Dividends}

The cost of the executive stock option depends on the executive's exercise policy. In the Markovian setting here, we can describe the exercise policy in terms of the so-called continuation region of the executive, the set of states in which he continues to hold the option. Formally, the value function for the executive's problem is

$$
f\left(W_{t}, S_{t}, t\right) \equiv \sup _{\left\{t \leq \tau \leq T, \pi^{m}, \pi^{s} \geq 0\right\}} \mathrm{E}_{t}\left\{V\left(W_{\tau}^{\pi}+n\left(S_{\tau}-K\right)^{+}, \tau\right)\right\}
$$

and the executive's continuation region is the set

$$
D \equiv\left\{(w, s, t): f(w, s, t)>V\left(w+n(s-K)^{+}, t\right)\right\}
$$

The nature of the present value-maximizing continuation region for an ordinary Amer- 
ican option is well known (see, for example, Kim (1990)). There exists a critical stock price boundary above which the option holder exercises and below which he waits. The boundary is increasing in the stock return volatility and time to expiration and decreasing in the dividend rate. For an executive stock option, some of these results may fail to hold. However, the dividend effect is the essentially the same.

Proposition 1 The executive's continuation region is larger the smaller the dividend rate on the stock.

Proof Suppose a given state $(w, s, t)$ is in the continuation region when the dividend rate is $\delta_{1}$ and let $\delta_{2}<\delta_{1}$. Let $f(w, s, t ; \delta)$ denote the value function and $S_{t}^{(\delta)}$ denote the stock price process when the dividend rate is $\delta$. For every strategy $\pi$ and $\tau$,

$$
V\left(W_{\tau}^{\pi}+n\left(S_{\tau}^{\left(\delta_{2}\right)}-K\right)^{+}\right) \geq V\left(W_{\tau}^{\pi}+n\left(S_{\tau}^{\left(\delta_{1}\right)}-K\right)^{+}\right)
$$

where $W^{\pi}$ denotes the outside wealth process under trading strategy $\pi$. This implies

$$
\sup _{\pi, \tau} \mathrm{E}_{t} V\left(W_{\tau}^{\pi}+n\left(S_{\tau}^{\left(\delta_{2}\right)}-K\right)^{+}\right) \geq \sup _{\pi, \tau} \mathrm{E}_{t} V\left(W_{\tau}^{\pi}+n\left(S_{\tau}^{\left(\delta_{1}\right)}-K\right)^{+}\right)
$$

SO

$$
f\left(w, s, t ; \delta_{2}\right) \geq f\left(w, s, t ; \delta_{1}\right)>V\left(w+n(s-K)^{+}\right)
$$

Therefore, $(w, s, t)$ is in the continuation region for $\delta_{2}$.

Note that this result holds regardless of the shape of the continuation region or the existence of a critical stock boundary. In numerical examples described later, option cost decreases in the dividend rate.

\section{Special Case with No Portfolio Choice}

To develop additional analytical results, we study the special case in which the portfolio choice is trivial. Consider the case in which the stock appreciates at the riskless rate,

$$
\frac{d S_{t}}{S_{t}}=(r-\delta) d t+\sigma d B_{t}
$$


and there is no other risky asset available. In this case, it is clear that after the executive exercises the options, his optimal portfolio contains only riskless bonds, so

$$
V\left(W_{t}, t\right)=U\left(W_{t} e^{r(T-t)}\right)
$$

Intuition suggests that even before the option is exercised, the executive's optimal outside portfolio contains no stock, since he would choose to short stock in the absence of a short sale constraint. We proceed with the assumption that investing outside wealth in bonds is optimal here. The executive's problem at each time $t<T$ then becomes

$$
f\left(S_{t}, t\right) \equiv \max _{\{t \leq \tau \leq T\}} \mathrm{E}_{t}\left\{U\left(n\left(S_{\tau}-K\right)^{+} e^{r(T-\tau)}+W\right)\right\}
$$

where the constant $W$ is outside wealth at time $\mathrm{T}$ and $f:(0, \infty) \times[0, T] \rightarrow \mathcal{R}$ is a continuous function satisfying $f\left(S_{t}, t\right) \geq U\left(n\left(S_{t}-K\right)^{+}+W\right)$ and $f\left(S_{T}, T\right)=U\left(n\left(S_{T}-\right.\right.$ $\left.K)^{+}+W\right)$.

Note that

$$
\begin{aligned}
\mathrm{E}\left[\sup _{0 \leq t \leq T} U\left(n\left(S_{t}-K\right)^{+} e^{r(T-t)}+W\right)\right] & =\mathrm{E}\left[U\left(\max _{0 \leq t \leq T}\left(n\left(S_{t}-K\right)^{+} e^{r(T-t)}+W\right)\right)\right] \\
& \leq U\left(\mathrm{E}\left[\max _{0 \leq t \leq T}\left(n\left(S_{t}-K\right)^{+} e^{r(T-t)}+W\right)\right]\right) \\
& <\infty
\end{aligned}
$$

so Theorem D.12 of Karatzas and Shreve (1998) implies that an optimal exercise time is

$$
\tau^{*} \equiv \inf \left\{t \in[0, T]: f\left(S_{t}, t\right)=U\left(n\left(S_{t}-K\right)^{+} e^{r(T-t)}+W\right)\right\}
$$

The continuation region for the problem is

$$
D=\left\{(s, t) \in(0, \infty) \times[0, T]: f(s, t)>U\left(n(s-K)^{+} e^{r(T-t)}+W\right)\right\}
$$

In the continuation region, $f(S, t)$ satisfies $E(d f)=0$. If $f$ is $C^{2,1}$ then, by Ito's Lemma, it satisfies the p.d.e.

$$
f_{t}+\frac{1}{2} \sigma^{2} S^{2} f_{S S}+(\mu-\delta) S f_{S}=0
$$

To calculate $f$ numerically, simultaneously determining the optimal exercise policy, we solve equation (21) backwards using an implicit finite difference method, similar to valuing 
an ordinary American option. The market value of the option, $P(S, t)$, solves the usual Black-Scholes equation,

$$
P_{t}+\frac{1}{2} \sigma^{2} S^{2} P_{S S}+(r-\delta) S P_{S}-r P=0
$$

subject to the exercise policy determined in solving for $f$.

\section{A. Existence of a Single Stock Price Boundary}

This section explores whether a single stock price boundary $\bar{s}(t)$ separates the continuation region below from the exercise region above, as is the case for ordinary American calls. This is often assumed to be true in executive stock option models with exogenously specified exercise policies. However, we show that the utility-maximizing policy need not have this structure and provide conditions under which it does.

To formalize intuition about the various effects of waiting to exercise, let $g(s, t) \equiv$ $U\left(n(s-K)^{+} e^{r(T-t)}+W\right)$ denote the payoff function for the optimal stopping problem and note that on $(K, \infty) \times[0, T], g$ is $C^{2,1}$ and Itô's lemma implies that $g$ has drift equal to $H\left(S_{t}, t\right)$ where

$$
H(s, t) \equiv U^{\prime}(h(s, t))(r K-\delta s) n e^{r(T-t)}+\frac{1}{2} U^{\prime \prime}(h(s, t)) n^{2} e^{2 r(T-t)} \sigma^{2} s^{2}
$$

and $h(s, t) \equiv n(s-K) e^{r(T-t)}+W$ is total time $T$ wealth given exercise at time $t$ and stock price $s$. This expression shows that when the option is in the money, the effects of waiting to exercise include the benefits of delaying payment of the strike price, the cost of losing dividends, and the cost of bearing stock price risk.

Proposition 2 Suppose that $W>n K e^{r T}$ and $H$ is nonincreasing in the stock price s. Then for each time $t \in[0, T)$, if there is any stock price at which exercise is optimal, then there exists a critical stock price $\bar{s}(t)$ such that it is optimal to exercise the option if and only if $S_{t} \geq \bar{s}(t)$.

Proof Fix $t \in[0, T)$. Suppose $\left(s_{1}, t\right)$ is a continuation point. We show that if $s_{2}<s_{1}$ then $\left(s_{2}, t\right)$ is also a continuation point. First note that it must be optimal to continue holding the option if $S_{t} \leq K$. Stopping then would guarantee a reward of $U(W)$, which is less than the expected utility of continuing, for example, until the first time the stock price rises to $K+c$, for some $c>0$, or until expiration $T$. 
So assume $s_{1}>s_{2}>K$. For $u \geq t$, let $S_{u}^{(i)}$ denote the stock price process starting from $s_{i}$ at time $t$ and note that $S_{u}^{(1)}>S_{u}^{(2)}$. Finally, let $\tau$ be the optimal stopping time given $S_{t}=s_{1}$. Since $\tau$ is a feasible strategy if $S_{t}=s_{2}$,

$$
\begin{aligned}
f\left(s_{2}, t\right)-f\left(s_{1}, t\right) & \geq \mathrm{E}_{t}\left\{U\left(n\left(S_{\tau}^{(2)}-K\right)^{+} e^{r(T-\tau)}+W\right)-U\left(n\left(S_{\tau}^{(1)}-K\right)^{+} e^{r(T-\tau)}+W\right)\right\} \\
& \geq \mathrm{E}_{t}\left\{U\left(n\left(S_{\tau}^{(2)}-K\right) e^{r(T-\tau)}+W\right)-U\left(n\left(S_{\tau}^{(1)}-K\right) e^{r(T-\tau)}+W\right)\right\} \\
& =g\left(s_{2}, t\right)-g\left(s_{1}, t\right)+\mathrm{E}_{t} \int_{t}^{\tau}\left(H\left(S_{u}^{(2)}, u\right)-H\left(S_{u}^{(1)}, u\right)\right) d u \\
& \geq g\left(s_{2}, t\right)-g\left(s_{1}, t\right) .
\end{aligned}
$$

Therefore, $f\left(s_{2}, t\right)-g\left(s_{2}, t\right) \geq f\left(s_{1}, t\right)-g\left(s_{1}, t\right)>0$.

Remark The hypothesis is satisfied for constant relative risk averse utility functions with relative risk aversion less than or equal to one and sufficiently large wealth. Similarly, in the value maximization problem for an ordinary option, the second order term in $H$ does not appear, the drift is nonincreasing in the stock price, and it follows that it is optimal to exercise if and only if the stock price has risen above a critical level. For executive stock options however, the risk aversion of the option holder gives rise to the second order term, and the drift need no longer be monotonic in the stock price.

Example with a split continuation region Figure 1 shows the optimal exercise policy for utility function

$$
U(W)=\frac{W^{1-A}}{1-A}+c W
$$

with $A=10, c=0.0001, K=1, T=10, r=0.05, \sigma=30 \%$, and $\delta=0$. The utility function is strictly increasing and strictly concave. As the figure shows, the executive exercises the option for intermediate stock prices, but does not exercise at either high or low stock prices. In this example, if we ignore the presence of the upper continuation region, the option cost is 0.408 instead of the correct value of 0.432 . Finally, we note that, with a positive dividend rate, there would also be another exercise region in this example, above the upper continuation region, extending to infinity.

Ahn and Wilmott (2003) find an example with a disconnected continuation region using a specialized HARA utility function and no outside wealth, but it requires that the appreciation rate on the stock exceed the riskless rate. This can distort the exercise policy when the model does not permit the executive to buy stock, because he may choose to continue holding the option as a substitute, even when doing so is value-destroying. 


\section{B. Risk Aversion, Wealth, and Volatility Effects}

This section describes how exercise policy and option cost change with risk aversion, wealth, and stock return volatility.

\section{B.1. Monotonicity with Respect to Risk Aversion and Wealth}

Intuition suggests that less risk averse managers are likely to exercise later, and consequently the cost of their options is greater. Similarly, one would expect that managers with decreasing absolute risk aversion will exercise later, implying greater option cost, if they have more nonoption wealth. The following results verify this intuition and hold regardless of the actual shape of the continuation region.

Proposition 3 An executive with less absolute risk aversion has a larger continuation region.

Proof If $U_{1}$ and $U_{2}$ are utility functions and $U_{2}$ has everywhere less absolute risk aversion than $U_{1}$, then by Theorem 5 on page 40 of Ingersoll (1987),

$$
U_{2}(W)=G\left(U_{1}(W)\right)
$$

where the function $G$ satisfies $G^{\prime}>0$ and $G^{\prime \prime}>0$. Now suppose a given state $(s, t)$ is in the continuation region with utility $U_{1}$ and let $\tau$ be the optimal stopping time for $U_{1}$. Let $f_{i}(s, t)$ and $g_{i}(s, t)$ denote the value and payoff functions for the problem with utility $U_{i}$. Since $\tau$ is feasible for the problem with $U_{2}$,

$$
\begin{aligned}
f_{2}(s, t)-g_{2}(s, t) & \geq \mathrm{E}_{t}\left\{U_{2}\left(n\left(S_{\tau}-K\right)^{+} e^{r(T-\tau)}+W\right)\right\}-U_{2}\left(n\left(S_{t}-K\right)^{+} e^{r(T-t)}+W\right) \\
& =\mathrm{E}_{t}\left\{G\left(U_{1}\left(n\left(S_{\tau}-K\right)^{+} e^{r(T-\tau)}+W\right)\right)\right\}-G\left(U_{1}\left(n\left(S_{t}-K\right)^{+} e^{r(T-t)}+W\right)\right) \\
& \geq G\left(\mathrm{E}_{t}\left\{U_{1}\left(n\left(S_{\tau}-K\right)^{+} e^{r(T-\tau)}+W\right)\right\}\right)-G\left(U_{1}\left(n\left(S_{t}-K\right)^{+} e^{r(T-t)}+W\right)\right) \\
& =G\left(f_{1}(s, t)\right)-G\left(g_{1}(s, t)\right) \\
& >0
\end{aligned}
$$

Therefore, $(s, t)$ is also in the continuation region for $U_{2}$.

Corollary 1 If the executive has decreasing absolute risk aversion, then the continuation region is larger with greater wealth. 
Proof Let $W_{2}>W_{1}$ and note that $U\left(w+W_{2}-W_{1}\right)=G(U(w))$ for some function $G$ satisfying $G^{\prime}>0$ and $G^{\prime \prime}>0$.

Proposition 4 If the dividend is zero, option cost is greater if the executive has less absolute risk aversion.

Proof Suppose $U_{1}$ and $U_{2}$ are utility functions and $U_{2}$ has everywhere less absolute risk aversion than $U_{1}$. For $i=1,2$, let $\tau_{i}$ be the optimal stopping time for the executive with utility $U_{i}$ and let $P_{i}$ be the resulting option cost. Finally, let

$$
p(s, t) \equiv e^{-r t}(s-k)
$$

By Proposition $3, \tau_{2} \geq \tau_{1}$, so

$$
\begin{aligned}
P_{2}-P_{1} & =\mathrm{E}\left\{p\left(S_{\tau_{2}}, \tau_{2}\right)^{+}-p\left(S_{\tau_{1}}, \tau_{1}\right)^{+}\right\} \\
& =\mathrm{E}\left\{\left(p\left(S_{\tau_{2}}, \tau_{2}\right)^{+}-p\left(S_{\tau_{1}}, \tau_{1}\right)^{+}\right) 1_{\left\{\tau_{1}<T\right\}}\right\} \\
& =\mathrm{E}\left\{\left(p\left(S_{\tau_{2}}, \tau_{2}\right)^{+}-p\left(S_{\tau_{1}}, \tau_{1}\right)\right) 1_{\left\{\tau_{1}<T\right\}}\right\} \\
& \geq \mathrm{E}\left\{\left(p\left(S_{\tau_{2}}, \tau_{2}\right)-p\left(S_{\tau_{1}}, \tau_{1}\right)\right) 1_{\left\{\tau_{1}<T\right\}}\right\} \\
& =\mathrm{E}\left\{\int_{\tau_{1}}^{\tau_{2}} e^{-r t}\left(r K d t+\sigma S_{t} d B_{t}\right) 1_{\left\{\tau_{1}<T\right\}}\right\} \\
& =\mathrm{E}\left\{\mathrm{E}_{\tau_{1}}\left\{\int_{\tau_{1}}^{\tau_{2}} e^{-r t}\left(r K d t+\sigma S_{t} d B_{t}\right)\right\} 1_{\left\{\tau_{1}<T\right\}}\right\} \\
& \geq 0
\end{aligned}
$$

Corollary 2 If the executive has decreasing absolute risk aversion and the dividend is zero, then option cost is greater with greater wealth.

Proof From Corollary 1, the optimal stopping time for an executive with greater wealth is later and the rest follows like the proof of Proposition 4.

In numerical examples with constant relative risk averse utility, option cost decreases in risk aversion and increases in wealth with a positive dividend as well. All of the examples described in this section are generated using an implicit finite difference method to solve the partial differential equations describing the executive value function and option cost. Even in examples in which the coefficient of relative risk aversion, $A$, is greater than one, or wealth is small, the continuation region is characterized by a single stock price boundary. 
Figures 2 and 3 illustrate these effects with plots of exercise boundaries and option cost for various levels of risk aversion and wealth. On the left, the exercise boundary for each level of risk aversion is a plot of the critical stock price $\bar{s}(t)$ versus time $t$. On the right, the option values, labeled "ESO," determined by the different boundaries are plotted against the level of risk aversion. Shown for comparison, the option value labeled "Max" is the value of the option under the usual present value-maximizing policy. In all of the figures, the number of options and initial stock price are normalized to one.

Consistent with Propositions 3 and 4 and Corollaries 1 and 2, the exercise boundaries fall with risk aversion and rise with wealth. The examples also suggest that as risk aversion grows large, or as outside wealth goes to zero, the boundary falls to $S=K$ and option value falls to zero (or the value of a European option that expires on the vesting date). The intuition for this is that as risk aversion grows large, the risk premium required to trade a certain exercise value for a risky continuation value goes to infinity. On the other hand, as risk aversion goes to zero, or as wealth grows large, option value converges to the present-value maximizing value.

\section{B.2. Non-Monotonicity with Respect to the Stock Return Volatility}

A basic result in standard option pricing theory is that option value is increasing in volatility. This is also typically the case in executive stock option models with an exogenously specified exercise boundary that does not change with volatility (see, for example, Cvitanić, Wiener, and Zapatero (2004)). However, the utility-maximizing continuation region can shrink considerably with volatility and this can lead to option value declining in volatility.

Figure 4 illustrates these effects with plots of the exercise boundaries and option values for various levels of stock return volatility. As volatility rises from $10 \%$ to $200 \%$, the exercise boundary tends to fall first and then rise slightly. This is shown most clearly in Figure 4a, with risk aversion coefficient $A=0.5$. The risk averse utility of the option payoff, as a function of the stock price, has both a convex region and a concave region, so in principle, an increase in volatility could either lead the executive to continue longer or exercise sooner. Apparently the concave portion dominates at low levels of volatility, making the executive exercise sooner as volatility rises. At higher levels of volatility, the convex portion seems to dominate and the boundary rises slightly. Empirically, Bettis,

Bizjak, and Lemmon (2005) find that options are exercised earlier at higher volatility firms. 
At the lower levels of risk aversion, as shown in Figures $4 \mathrm{a}$ and $4 \mathrm{~b}$, executive stock option value is generally increasing in volatility. However, at higher levels of risk aversion, as shown in Figures 4c and 4d, executive stock option value is decreasing in volatility at low levels of volatility. Here the negative effect on value of the drop in the boundary of offsets the positive effect of extreme stock prices becoming more likely.

\section{General Case with Outside Portfolio Choice}

This section examines the general problem with nontrivial outside portfolio optimization described in Section II. Allowing for optimal investment of outside wealth in the market, the value function is now a function of both the stock price and outside wealth. In the continuation region, $f(W, S, t)$ satisfies $E(d f)=0$. If $f$ is sufficiently smooth, then, by Itô's Lemma, it satisfies the p.d.e.

$$
\begin{aligned}
f_{t}+f_{W}\left[r W+\pi^{m}(\mu-r)\right]+ & S f_{S}(\lambda-\delta)+\frac{1}{2} f_{W W}\left(\pi^{m}\right)^{2} \sigma_{m}^{2} \\
+ & \frac{1}{2} S^{2} f_{S S} \sigma^{2}+S f_{W S} \pi^{m} \rho \sigma \sigma_{m}=0
\end{aligned}
$$

where, from the first-order condition, the optimal investment in the market, $\pi^{m}$, is given by

$$
\pi^{m}=\frac{-(\mu-r) f_{W}-S \rho \sigma \sigma_{m} f_{W S}}{\sigma_{m}^{2} f_{W W}}
$$

The option's market value, $P(W, S, t)$ satisfies the p.d.e.

$$
\begin{aligned}
P_{t}+W r & P_{W}+S P_{S}(r-\delta)+\frac{1}{2} P_{W W}\left(\pi^{m}\right)^{2} \sigma_{m}^{2} \\
+ & \frac{1}{2} S^{2} P_{S S} \sigma^{2}+S P_{W S} \pi^{m} \rho \sigma \sigma_{m}-r P=0
\end{aligned}
$$

subject to the exercise policy determined in solving for $f$. We solve equations (35) and (36) simultaneously using an explicit finite difference method. To enforce stability, it is necessary to place a bound on the magnitude of the weight on the market in the outside portfolio in order to bound the portfolio volatility. When outside wealth is large relative to option wealth, that constraint is not binding, but the constraint impacts the results when outside wealth is small. The constraint is potentially relevant empirically because it corresponds to constraints on borrowing and short-selling. 
Unreported results suggest that the wealth, risk aversion, and volatility effects from the last section still hold in the presence of optimal trading in a market portfolio with a nonzero risk premium and correlation with the stock return. In particular, option value is still increasing with executive wealth, decreasing with executive risk aversion, and potentially non-monotonic with respect to stock return volatility. In addition, the optimal exercise policy appears to be characterized by a critical stock price for each possible date and wealth level, above which it is optimal to exercise and below which it is optimal to continue. We also note that when the market risk premium and the stock return correlation with the market are set to zero, then optimal market portfolio weight in the outside portfolio is zero, and the results are the same as those from the one-factor model of the last section.

The remainder of this section focuses on the dependence of the exercise policy and option value on the degree of correlation between the stock return and the return on the market. The results below disentangle the correlation effects from those of the portfolio constraint.

\section{A. Correlation Effects with Zero Market Risk Premium}

Intuition suggests that when the market risk premium $\mu$ is zero, the only reason to hold a market position in the outside portfolio is to hedge the option position. Furthermore, all that should matter for the option exercise policy and value is the magnitude of the correlation, $\rho$, not the sign, since that is what determines how much stock risk can be hedged away.

Figures 5a and 5b confirm this intuition. Exercise boundaries and option values for a given value of $\rho$ are the same as for $-\rho$. To ease comparison with the last section, the figures show exercise boundaries across time for wealth equal to its initial value. The examples fix the riskless rate at $5 \%$, the market return volatility at $20 \%$, the stock return volatility at $50 \%$, and the stock dividend at zero. The figures use the expression $\mathrm{Pi} \_\mathrm{m} \equiv \pi^{m} / W$.

Figure 5a illustrates exercise boundaries and option values in the case that outside wealth is large relative to the option position. Initial wealth is six times the value of shares under option, so that the portfolio constraint $\left|\pi^{m} / W\right| \leq 2$ is very loose. The level of executive risk aversion is also set high, $A=10$, to make the amount of absolute risk aversion, $A / W$, comparable to that in some of the examples in the previous section. In 
this case, as the magnitude of correlation approaches one, the continuation region grows large and the option value approaches its maximized value, i.e., its Black-Scholes value. Indeed, if the executive can hedge the option position perfectly, there is no reason for a value-destroying early exercise.

Figure 5a also shows the effect of tightening the portfolio constraint to $\left|\pi^{m} / W\right| \leq 0.25$ or $\left|\pi^{m} / W\right| \leq 0.10$. Tightening the constraint uniformly reduces exercise boundaries and option values because it leaves the option holder exposed to more unwanted option risk. The impact of tightening the constraint is greater for larger correlation, because the larger the correlation, the larger market position the option holder would like to hold to hedge the option. Still, the effect of the portfolio constraint depends only on the magnitude of the correlation, not the sign. It has no impact when correlation is zero, because the optimal market position is zero in that case.

Figure 5b illustrates exercise boundaries and option values in the case that outside wealth is small relative to the option position. Here, initial wealth is 1.2 times the value of shares under option, which is the same as in the previous section in cases where terminal wealth is set equal to 2 , and risk aversion $A=2$. Because outside wealth is smaller relative to option wealth, relatively larger proportional market positions are necessary to hedge the option. Therefore, the portfolio constraint, $\left|\pi^{m} / W\right| \leq 2$, which was loose before, is tight here, and the exercise boundaries and option values are similar to those in the case of larger wealth but tighter portfolio constraint.

\section{B. Correlation Effects with Nonzero Market Risk Premium}

When the market risk premium is positive, the executive would optimally choose a long position in the market in the absence of the option position. The risk premium on the stock is equal to its normal level, i.e., the stock's market beta times the market risk premium. Thus the stock can be regarded as a portfolio containing the market and a risky idiosyncratic component that carries zero risk premium. Intuition suggests that in the absence of a constraint on the outside portfolio market weight, the executive will set the weight so as to hedge away the market component in the option position, and then incrementally increase the weight to the desired market exposure. In particular, at the optimum, the executive's net exposure to the market and the idiosyncratic risk of the option position should depend only on the magnitude of the correlation, not the sign. Therefore, in the absence of a portfolio constraint, correlation effects on exercise boundaries and 
option values should be the same as in the case of zero market risk premium. That is, boundaries and option values should rise with the magnitude of correlation, independent of the sign, as more and more of the option risk can be hedged away, and the option value therefore approaches its maximized value.

Consistent with this intuition, the left plot of Figure $5 \mathrm{c}$, in which wealth is high, shows that when the portfolio constraint is loose, $\left|\pi^{m} / W\right| \leq 2$, the correlation effects on option value are virtually the same as in the case of zero market risk premium depicted in Figure 5a. Now, however, the impact of tightening the portfolio constraint is not symmetric in $\rho$. It is still the case that tightening the constraint uniformly reduces boundaries and option values. But the effect is greater when the correlation is negative than when it is positive. There are two reasons for this. First, the natural net market position is positive, so the constraint leaves less room for the incremental long position needed for hedging when the correlation is negative than it leaves for the incremental short position needed for hedging when the correlation is positive. Second, the unhedged market risk inherent in the option position carries a negative risk premium when the correlation, and thus beta, is negative, while it carries a positive risk premium when the correlation is positive. The effect of the negative risk premium associated with negative correlation and unhedgeable market risk can ultimately outweigh the benefits of partially hedging, so that when the portfolio constraint is very tight, option value can even decrease as correlation falls from zero to minus one. This is illustrated in the left plot of Figure 5 c for the case $\left|\pi^{m} / W\right| \leq 0.10$.

In the right plot of Figure $5 \mathrm{c}$, outside wealth is lower relative to option wealth, which effectively makes the portfolio constraint $\left|\pi^{m} / W\right| \leq 2$ tighter. Thus, the correlation effect is comparable to that in the case of larger wealth but a tighter portfolio constraint. In particular, option value is now monotonically increasing in correlation, as in the case of initial wealth equal 6 and $\left|\pi^{m} / W\right| \leq 0.10$ shown in the left plot.

Figure 5d supports this reasoning by verifying that when the market risk premium is negative, the portfolio constraint is tighter for positive correlation. Indeed, the option values for a given $\rho$ when the market risk premium is $-8 \%$ are exactly the same as for $-\rho$ when the risk premium is $8 \%$.

To summarize, the results of this section suggest that in the absence of constraints on the outside portfolio weight in the market, option values and exercise boundaries increase with the magnitude of the correlation between the stock return and the market return, independent of the sign of the correlation, and approach their levels under a valuemaximizing policy. Imposing a bound on the magnitude of the market weight reduces 
boundaries and option values because it leaves the executive exposed to more option risk and thus precipitates earlier exercise. When the market risk premium is positive, the impact of the bound is greater for negative correlation than positive correlation, so much so that option value can change from a U-shaped function of correlation to a monotonic increasing function of correlation. This is because when the natural market position is positive, the bound places a tighter constraint on the incremental long position needed to hedge in the case of negative correlation than the constraint on the incremental short position needed for hedging when correlation is positive. Moreover, the unhedged market position in the option carries a negative risk premium when the stock beta is negative, making the option position even less tolerable. In the empirically relevant range with nonnegative market risk premium and nonnegative correlation between the stock return and the market return, we find that option value is unambiguously increasing in correlation.

\section{The FASB Approximation}

In December 2004, the FASB issued SFAS 123(R), which requires firms to recognize

option cost in earnings. The new standard requires firms to estimate option cost according to "established principles of financial economic theory" when market prices are unavailable. However, recognizing that full-blown estimation methods are still only beginning to develop, the FASB illustrates a variety of acceptable methods for approximating option cost, which include lattice methods and an adjusted Black-Scholes-Merton formula. The vast majority of firms use the latter method, which entails first estimating the option's expected term (conditional on vesting) and then valuing the option at its Black-ScholesMerton value using the option's expected term in place of its contractual term. (This amount is then multiplied by the probability that the option vests, and later updated to reflect the actual number of pre-vesting forfeitures.) Equilar (2007) finds that 88\% of Fortune 1000 firms used this method in 2006.

To see how the approximation works in the setting here, we compute the expected option term implied by the exercise policy of the executive in this model and then calculate the FASB approximation. The expectation of the option's term is under the true probability measure, as would be estimated using historical data on realized option lives according to the FASB guidelines. Table I presents expected terms, FASB approximations, exact option values, labeled ESO value, and approximation errors for a variety of 
parameterizations of the model. We start with two different base case parameterizations. The first is for a firm with high volatility, high beta, and low dividend rate, which might be typical of a young firm or a technology firm. The second is for a lower volatility, lower beta, higher dividend firm, such as a more seasoned firm in the industrial sector. Then we alternately vary the beta, the volatility, and the dividend rate of the base case firms, to show different effects in the cross-section. Throughout the examples, the risk free rate is $5 \%$, the expected return on the market portfolio is $13 \%$, and the volatility of the market return is $20 \%$. The option vests at year 2 and expires at year 10 . The executive's coefficient of relative risk aversion is four and outside wealth is 0.6 times the grant date value of shares under option. This gives the options expected terms of about 5 years in the base cases, which is the average expected term used by Fortune 1000 firms from 2004 to 2006, according to Equilar (2007).

Panel A of Table I shows the effect of increasing the stock's beta, or equivalently, its correlation with the market, since volatility is held constant in this panel. As explained in Section IV, increasing this correlation improves the executive's ability to hedge option risk, which makes him willing to hold the option longer, i.e., raises the exercise boundary, and this increases the option's present value. The columns labeled ESO value show option values increasing as beta increases from zero to 1.4. On the other hand, there are conflicting effects on the option expected term. On one hand, raising the boundary should increase the option expected term. On the other hand, when beta increases, the expected return on the stock rises commensurately, which reduces the time to reach the boundary. For the first base case, the latter effect dominates, and option expected life and the FASB approximation decline as beta rises, moving in the opposite direction as the ESO value. In the second case, the expected term is $\mathrm{u}$-shaped in beta, but the approximation error still decreases in algebraic value monotonically.

Panels B and C of Table I show the effects of changing stock return volatility. Panel B shows the effect with beta held constant, in which case only the idiosyncratic component of the stock risk is varying. Panel $\mathrm{C}$ shows the effect with correlation held constant, in which case the idiosyncratic and hedgeable components of risk are held in constant proportion, such as in the case of an increase in leverage. Like the examples from Section III, the ESO values are either increasing or u-shaped in volatility, as are the FASB approximations. However, the FASB approximation rises faster with volatility, so the approximation error is increasing in algebraic value. The effect is less pronounced in Panel $\mathrm{C}$ for two reasons. First, in Panel C, some of the increase in risk is an increase in hedgeable risk, which has 
a positive effect on the exercise boundary and ESO value, because of the convexity of the option payoff, without the corresponding negative effect of increased net risk exposure. Second, in the FASB approximation in Panel C, there is the negative effect of increasing beta which increases the stock's expected return and reduces the option's expected term. Thus the approximation error increases more slowly in Panel C than in Panel B.

Finally, Panel D of Table I shows dividend effects. Both ESO values and FASB approximations decline as the dividend increases. In the low end of the dividend range, the FASB value declines faster, so the approximation error decreases in algebraic value. As the dividend grows large, both the ESO value and FASB approximation converge to zero.

The effects illustrated here assume the executive follows the exercise policy determined by our model. Analyzing the actual FASB approximation errors that occur in practice requires knowing the actual exercise policies of executives, from which both correct option values and expected option terms could be estimated. Overall, the table suggests that FASB approximation errors can be small or large, positive or negative, depending on the firm profile.

\section{Subjective Option Value}

The focus of the paper is on the cost of the option to the firm, that is, the present value of the option payoff from the viewpoint of market participants who can trade freely. However, we can also use our framework to examine the subjective value of the option from the viewpoint of the executive who cannot trade the option. We define the subjective option value as the amount of freely investable money that would give the executive the same utility as the option. This is value of $x$ such that

$$
V(W+x, t)=f(W, S, t)
$$

where $V$ is the indirect utility value of freely investable wealth as defined in equation (6) and $f$ is the value function for the executive's problem with the options. This definition is consistent with that in Kaul, Liu, and Longstaff (2003) for the subjective value of restricted stock.

Proposition 5 As long as the executive is free to buy the option, either explicitly or synthetically, the option's subjective value cannot exceed its present value. 
Proof If the executive were given an amount of cash equal to the option's present value, the executive could always buy the option in the open market, so the executive could get at least as much utility as with the option itself. Therefore, the executive would need no more than the present value of the option, in the form of freely investable cash, to be as well off as with the option.

While Section 16-c of the Securities Exchange Act prohibits insiders from taking short positions in the stock, either directly or with option positions, there is no prohibition on long positions, so the result above should generally hold in practice. Violations of this inequality can arise if the executive is not allowed to take long stock or market positions in his outside portfolio.

In Table II we use our model to quantify subjective option values and their discounts from present value for the same parameterizations shown in Table I. The discount is defined as one minus the ratio of subjective value to present value. Panel A shows that like present values, subjective option values increase with beta, or correlation, and the discount declines. Intuitively, better hedging opportunities narrow the gap as the executive can effectively monetize more and more of the option's value. Kaul, Liu, and Longstaff (2003) find a similar effect in the subjective value of restricted stock.

In Panel $\mathrm{B}$, subjective option values are monotonically decreasing, and the discount is increasing, as the executive is exposed to more and more idiosyncratic risk. This is similar to the idiosyncratic risk effects in Kaul, Liu, and Longstaff (2003) and Henderson (2005). In Panel C, where correlation is held constant, subjective option value does not vary monotonically with volatility in the second base case. In this panel, in addition to the apparently negative effect of the increase in idiosyncratic risk, there is also the positive effect of an increase in market risk, which essentially increases the value of the tradeable component of the option payoff. Henderson (2005) finds a similar effect with a European option. In the second base case, this positive effect dominates at low volatility. The positive effect also operates on the exercise boundary and the option value, however, and the subjective value discount remains increasing in volatility.

Panel D shows that increasing the dividend rate reduces the subjective option value. The discount is roughly constant at the low end of the dividend range. However, as the dividend grows large, both option cost and subjective value go to zero, and the discount appears to go to zero as the option becomes a smaller and smaller component of wealth.

The difference between the cost of the option to the firm and its subjective value to the employee is part of the cost of extracting better performance. In the language 
of the principal-agent literature, it is the cost of the inefficient risk allocation necessary to elicit unobservable or noncontractible effort. In addition to this, there is the cost of compensating the executive for the extra effort, which must be paid even if the effort is contractible and the extra compensation can be paid in cash. The results in Table II suggest that the total cost of eliciting better performance may be quite high. On the other hand, evidence of positive stock price reactions to announcements of the adoption of an option plan in Brickley, Bhagat, and Lease (1985), DeFusco, Johnson, and Zorn (1990), and Langmann (2007) suggests that the market perceives the benefits to outweigh the costs.

\section{Summary and Conclusions}

This paper advances the theory of executive stock option valuation with an in-depth study of the optimal exercise policy of a risk averse executive and its implications for option cost. Many recent valuation models for executive stock options set the exercise policy exogenously, assuming a single stock price boundary. This paper provides a simple example showing that the optimal exercise policy need not be of that form. However, when riskless bonds are the only investment available and the stock underlying the option appreciates at the riskless rate, we provide a sufficient condition for the existence of a single boundary. This condition is satisfied by constant relative risk averse utility functions with risk aversion coefficient less than or equal to one, and we find no counterexamples among our numerical results for constant relative risk averse utility functions with risk aversion coefficient greater than one.

We also prove that the executive exercises later and option cost is greater when he has less absolute risk aversion, or more wealth combined with decreasing absolute risk aversion. He also exercises later the lower the dividend rate on the stock. All these monotonicity results hold regardless of the exact shape of the continuation region.

Numerical examples with constant relative risk averse utility show how the exercise boundary and option value vary with volatility. In contrast to results from standard option theory, or from executive stock option valuation models with a fixed exercise boundary, executive stock option value can decline in stock return volatility when increases in volatility cause the optimal exercise boundary to drop sufficiently.

Next, we show numerically how exercise boundaries and option values vary with stock beta and portfolio constraints when trading outside wealth in the market is possible. 
When the market risk premium and stock beta are nonnegative, option value increases with the stock beta and decreases as portfolio constraints are tightened.

Finally, we examine the widely used approximation to option cost that is accepted by the FASB and find the approximation error can be small or large, positive or negative, depending on the firm's beta, volatility, and dividend rate. In addition, we tabulate subjective option values from the executive's viewpoint and show how the subjective discount varies with firm profile. Our results suggest that the cost of providing performance incentives is high and we conclude that the performance benefits must be quite significant. 


\section{References}

Ahn, Hyungsok, and Paul Wilmott, 2003, On exercising American options: The risk of making more money than you expected, Wilmott Magazine March, 52-63.

Bettis, J. Carr, John M. Bizjak, and Michael L. Lemmon, 2001, Managerial ownership, incentive contracting, and the use of zero-cost collars and equity swaps by corporate insiders, Journal of Financial and Quantitative Analysis 36, 345-370.

Bettis, J. Carr, John M. Bizjak, and Michael L. Lemmon, 2005, Exercise behavior, valuation, and the incentive effects of employee stock options, Journal of Financial Economics 76, 445-470.

Black, Fischer, and Myron S. Scholes, 1973, The pricing of options and corporate liabilities, Journal of Political Economy 81, 637-659.

Brickley, James A., Sanjai Bhagat, and Ronald C. Lease, 1985, The impact of longrange managerial compensation plans on shareholder wealth, Journal of Accounting and Economics 7, 115-129.

Cai, Jie, and Anand M. Vijh, 2005, Executive stock and option valuation in a two statevariable framework, Journal of Derivatives Spring, 9-27.

Carpenter, Jennifer N., 1998, The exercise and valuation of executive stock options, Journal of Financial Economics 48, 127-158.

Carr, Peter, and Vadim Linetsky, 2000, The valuation of executive stock options in an intensity based framework, European Financial Review 4, 211-230.

Cuny, Charles J., and Philippe Jorion, 1995, Valuing executive stock options with an endogenous departure decision, Journal of Accounting and Economics 20, 193-205.

Cvitanić, Jakša, Zvi Wiener, and Fernando Zapatero, 2004, Analytic pricing of executive stock options, Working paper, University of Southern California.

DeFusco, Richard A., Robert R. Johnson, and Thomas S. Zorn, 1990, The effect of executive stock options on stockholders and bondholders, Journal of Finance 45, 617-627.

Detemple, Jérôme, and Suresh Sundaresan, 1999, Nontraded asset valuation with portfolio constraints: A binomial approach, Review of Financial Studies 12, 835-872. 
Equilar, 2007, 2007 Equity report: An analysis of equity compensation practices at Fortune 1000 companies.

Financial Accounting Standards Board, 2004, Statement of Financial Accounting Standards no. 123 (revised 2004): Share based payment, Financial Accounting Series 263-C, $1-286$.

Frydman, Carola, and Raven E. Saks, 2007, Executive compensation: A new view from a long-term perspective, Working paper, Massachusetts Institute of Technology.

Geske, Robert, 1979, A note on an analytic valuation formula for unprotected American call options on stocks with known dividends, Journal of Financial Economics 7, 375380.

Grasselli, M. R., 2006, Nonlinearity, correlation, and the valuation of employee options, Working paper, McMaster University.

Hall, Brian, and Kevin Murphy, 2002, Stock options for undiversified executives, Journal of Accounting and Economics 33, 3-42.

Henderson, Vicky, 2004, Valuing the option to invest in an incomplete market, Working paper, Princeton University.

Henderson, Vicky, 2005, The impact of the market portfolio on the valuation, incentives, and optimality of executive stock options, Quantitative Finance 5, 35-47.

Henderson, Vicky, 2006, Executive exercise explained: Patterns for executive stock options, Working paper, Princeton University.

Huddart, Steven, 1994, Employee stock options, Journal of Accounting and Economics $18,207-231$.

Hull, John, and Alan White, 2004, How to value employee stock options, Financial Analysts Journal 60, 114-119.

Ingersoll, Jonathan, 1987, Theory of Financial Decision Making (Rowman \& Littlefield, Totowa, New Jersey).

Ingersoll, Jonathan, 2006, The subjective and objective evaluation of incentive stock options, Journal of Business 79, 453-487. 
Jain, Ashish, and Ajay Subramanian, 2004, The intertemporal exercise and valuation of employee options, The Accounting Review 79, 705-743.

Jennergren, L. Peter, and Bertil Näslund, 1993, A comment on "Valuation of executive stock options and the FASB proposal", The Accounting Review 68, 179-183.

Kadam, Ashay, Peter Lakner, and Anand Srinivasan, 2003, Executive stock options: Value to the executive and cost to the firm, Working paper, New York University.

Karatzas, Ioannis, and Steven E. Shreve, 1998, Methods of Mathematical Finance (Springer-Verlag, New York).

Kaul, Matthias, Jun Liu, and Francis A. Longstaff, 2003, Paper millionaires: How valuable is stock to a stockholder who is restricted from selling it?, Journal of Financial Economics 67, 385-410.

Kim, In Joon, 1990, The analytic valuation of American options, Review of Financial Studies 3, 547-572.

Lambert, Richard A., David F. Larcker, and Robert E. Verrecchia, 1991, Portfolio considerations in valuing executive compensation, Journal of Accounting Research 29, 129 149.

Langmann, Christian, 2007, Stock market reaction and stock option plans: Evidence from Germany, Schmalenbach Business Review 59, 85-106.

Leung, Tim, and Ronnie Sircar, 2007, Accounting for risk aversion, vesting, job termination risk and multiple exercises in valuation of employee stock options, Working paper, Princeton University.

Marcus, Alan, and Nalin Kulatilaka, 1994, Valuing employee stock options, Financial Analysts Journal 50, 46-56.

Merton, Robert C., 1973, Theory of rational option pricing, Bell Journal of Economics and Management Science 4, 141-183.

Miao, Jianjun, and Neng Wang, 2005, Investment, consumption and hedging under incomplete markets, Working paper, Columbia University. 
Rogers, L. C. G., and José Scheinkman, 2007, Optimal exercise of executive stock options, Finance and Stochastics 11, 357-372.

Roll, Richard, 1977, An analytic valuation formula for unprotected American call options on stocks with known dividends, Journal of Financial Economics 5, 251-258.

Rubinstein, Mark, 1995, On the accounting valuation of employee stock options, Journal of Derivatives 3, 8-24.

Van Moerbeke, Pierre, 1976, On optimal stopping and free boundary problems, Archives of Rational Mechanical Analysis 60, 101-148.

Whaley, Robert E., 1981, On the valuation of American call options on stocks with known dividends, Journal of Financial Economics 9, 207-211. 


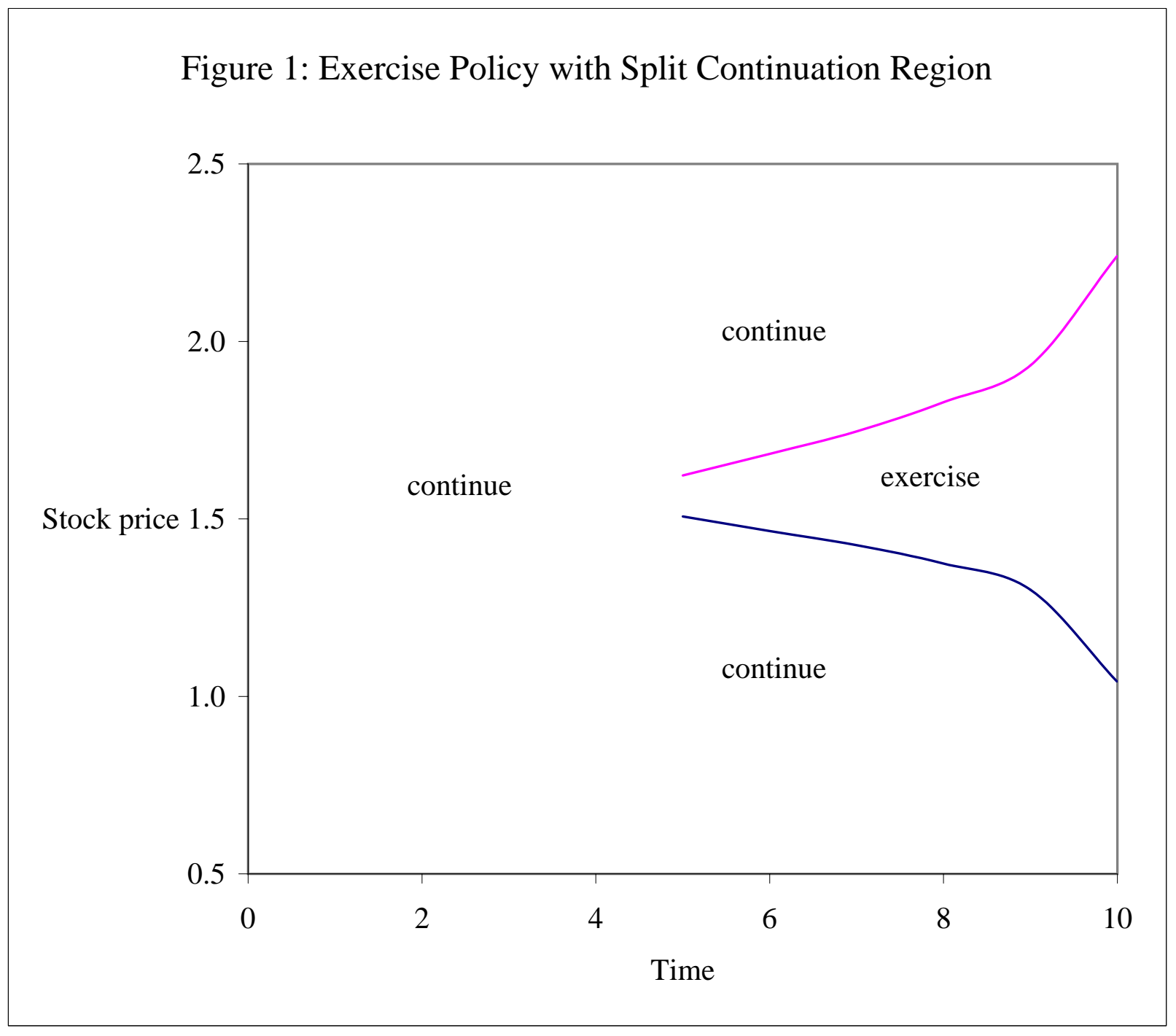


Figure 2: Exercise Boundaries and Option Values for Various Levels of Risk Aversion Initial wealth $=1.2$, Volatility $=50 \%$, Dividend $=3 \%$
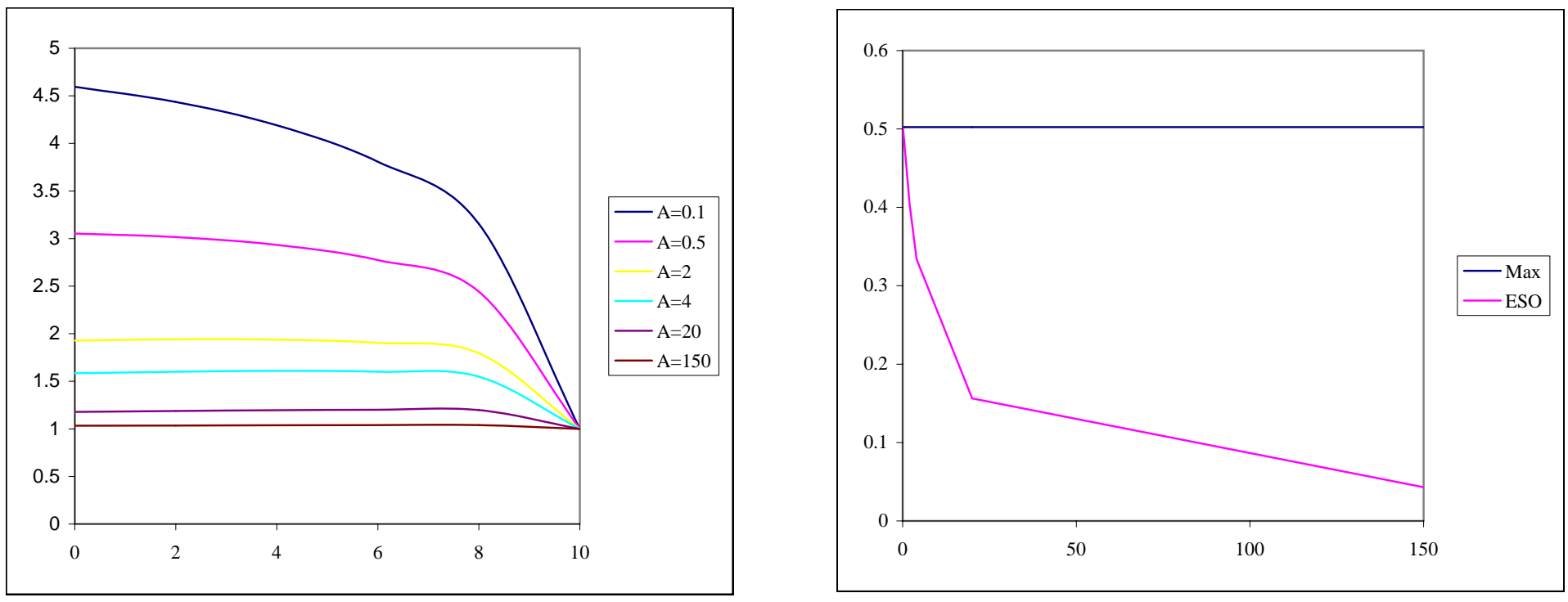

Figure 3: Exercise Boundaries and Option Values for Various Levels of Wealth

Risk aversion $=2$, Volatility $=50 \%$, Dividend $=3 \%$
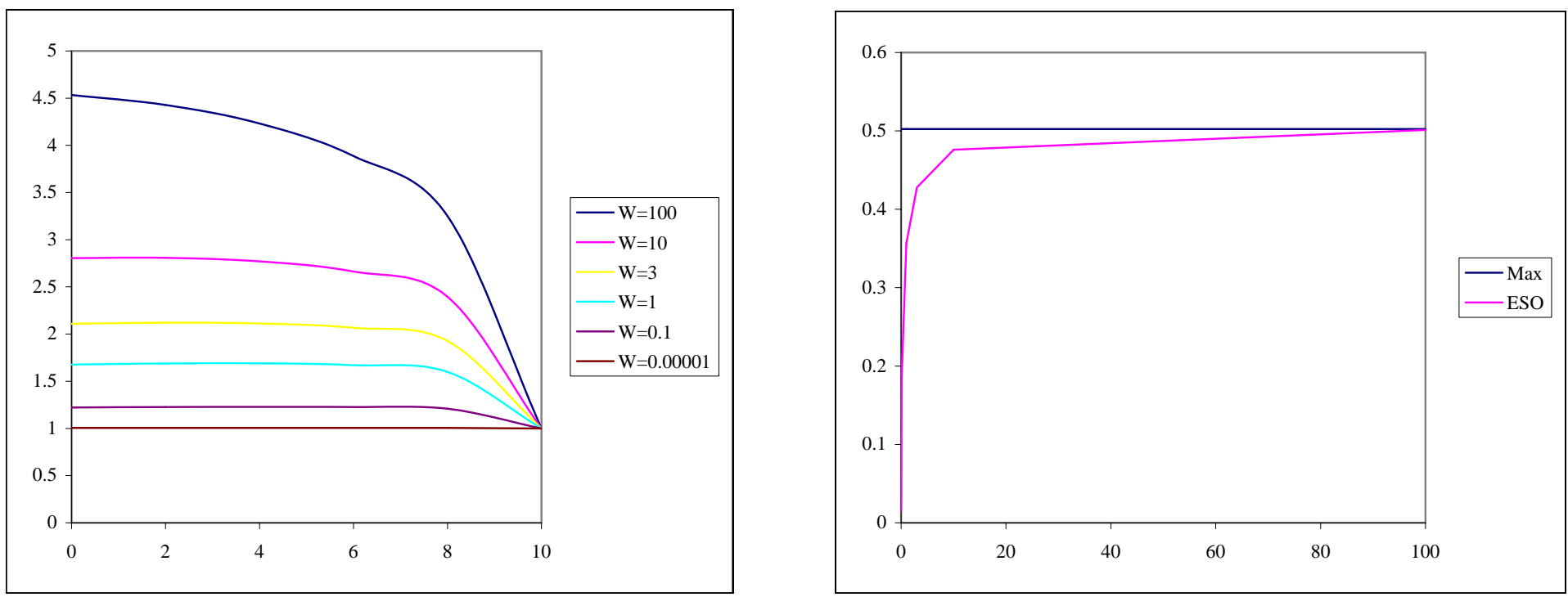
Figure 4: Exercise Boundaries and Option Values for Various Levels of Stock Volatility

a. Risk aversion coefficient $=0.5$

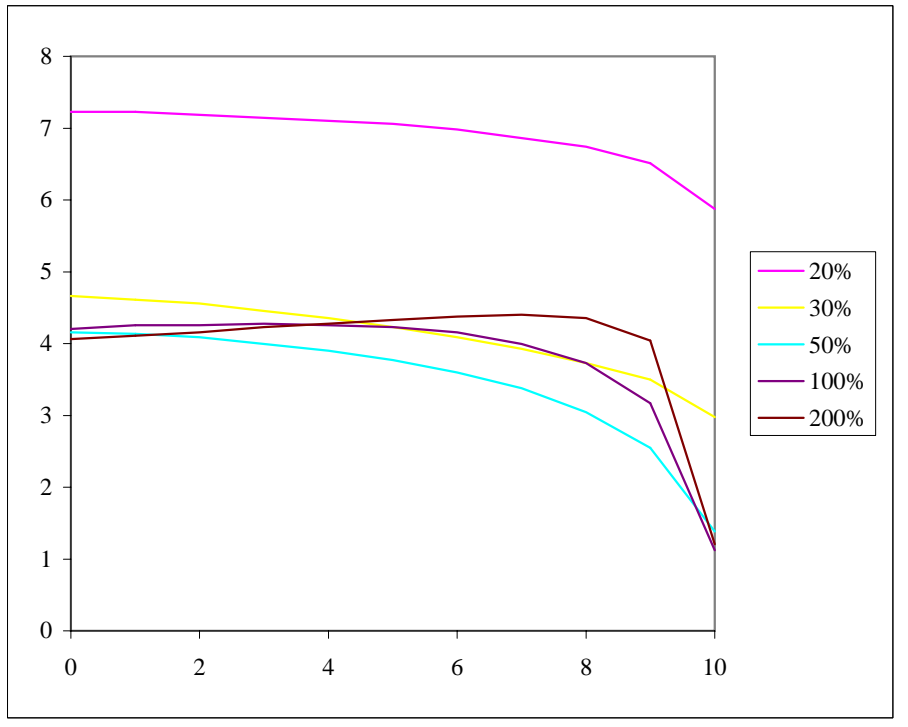

b. Risk aversion coefficient $=2$

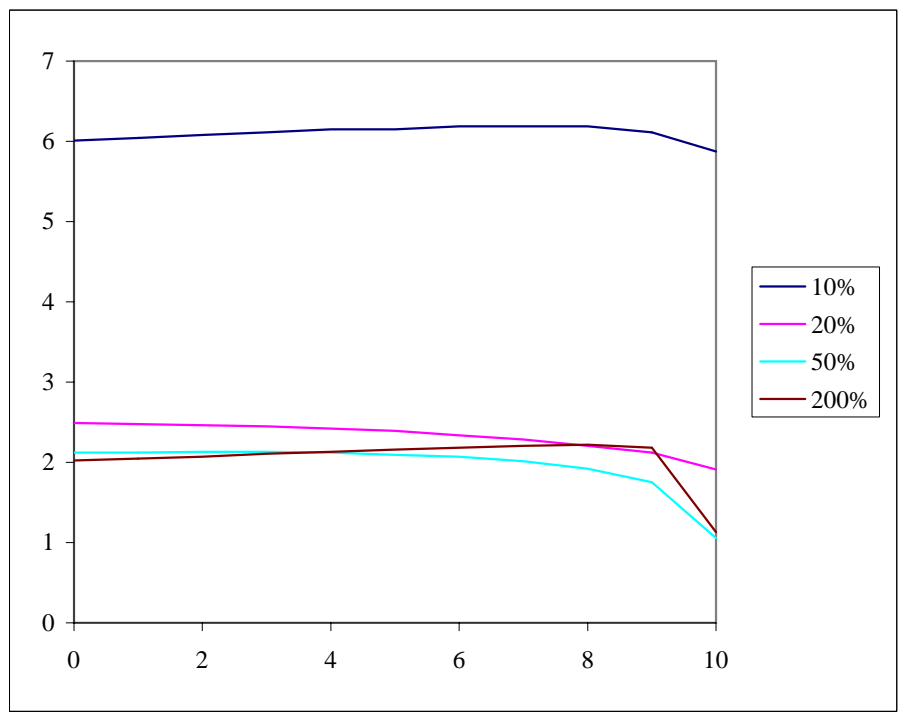

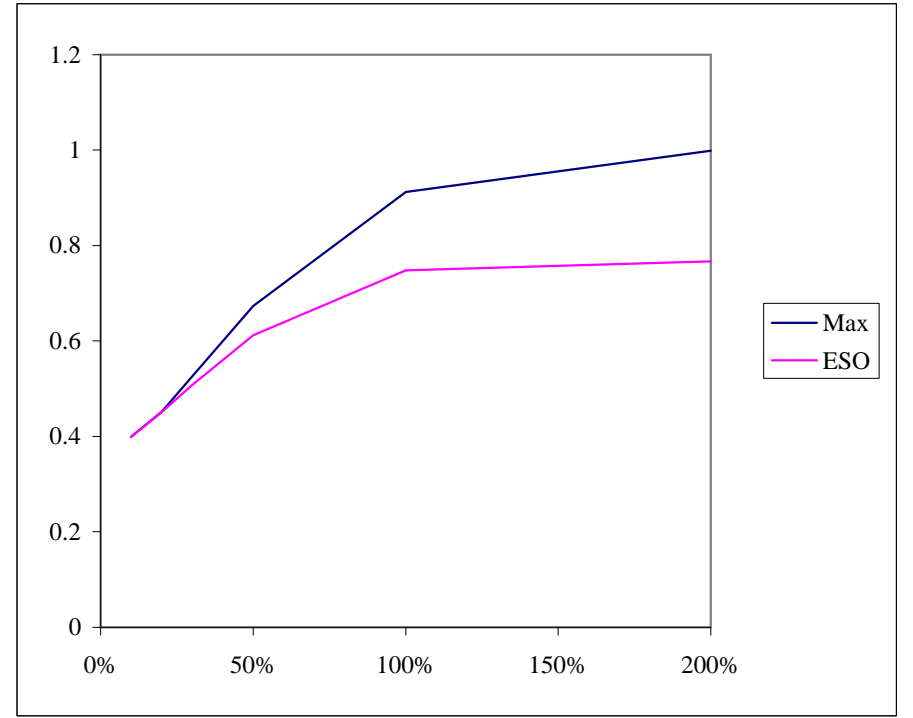

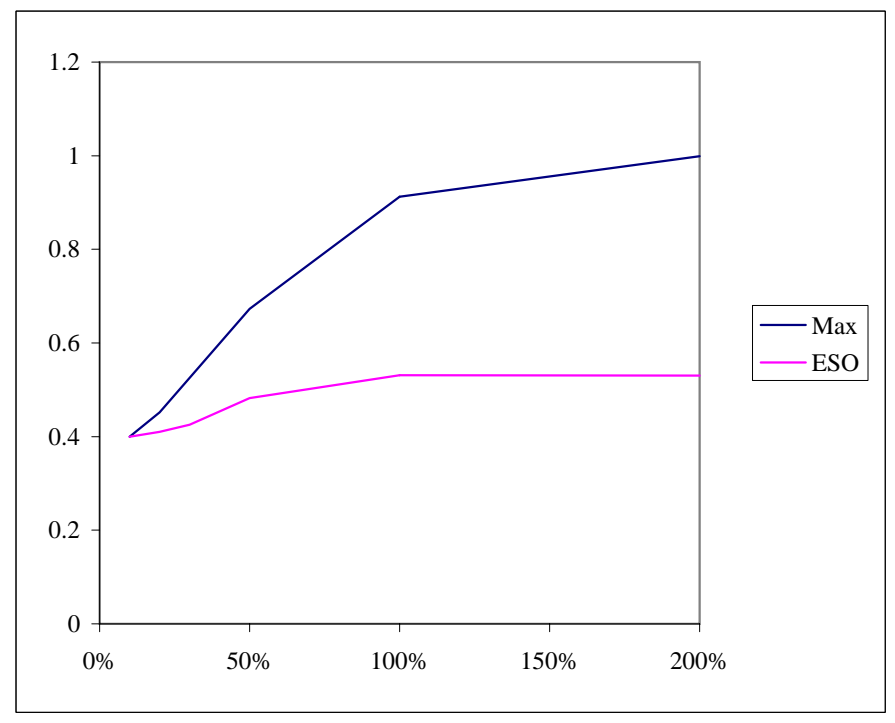


Figure 4 cont'd: Exercise Boundaries and Option Values for Various Levels of Stock Volatility

c. Risk aversion coefficient $=4$

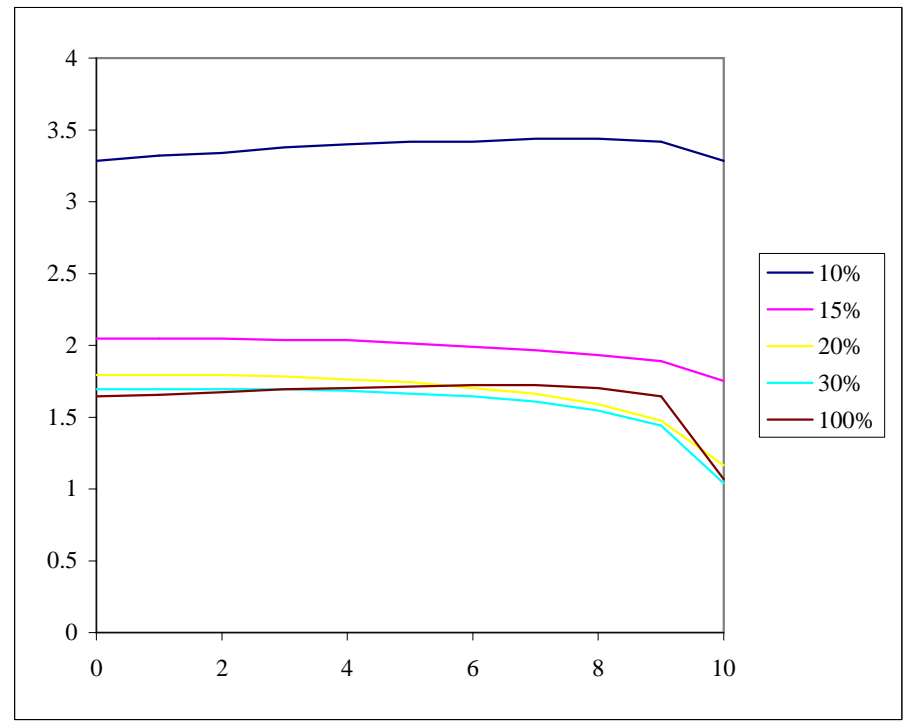

d. Risk aversion coefficient $=10$

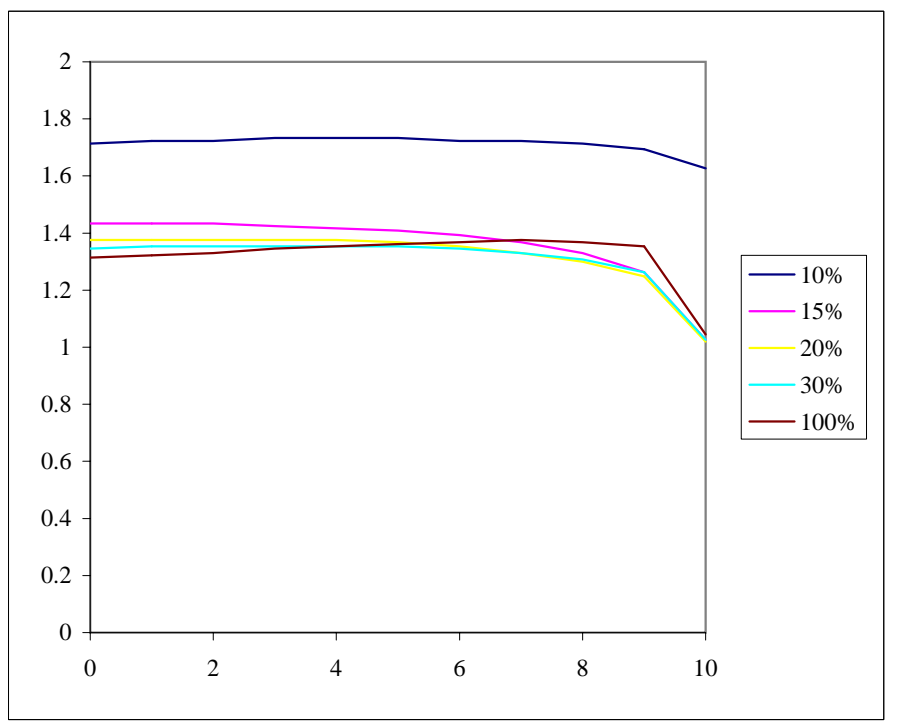

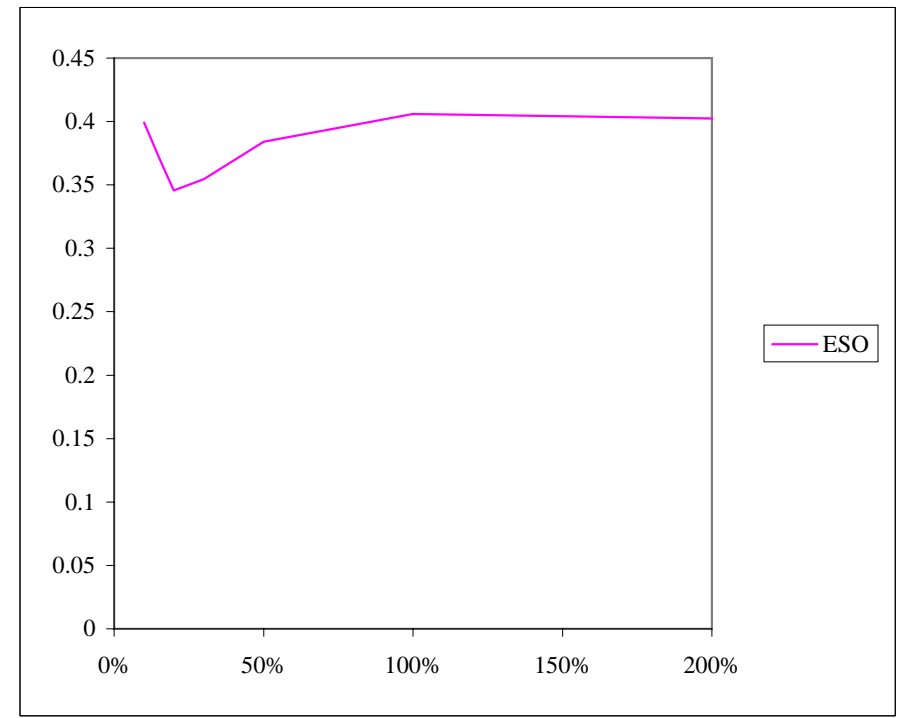

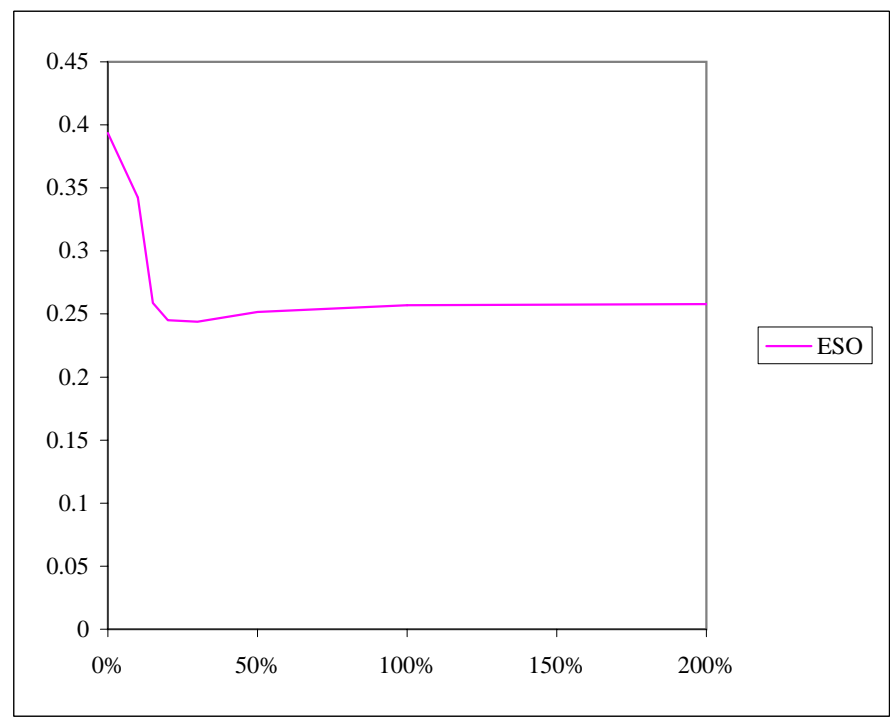


Figure 5: Exercise Boundaries and Option Values for Various Levels of Stock-Market Correlation

a. Market risk premium $=0$, Initial wealth $=6$, Risk aversion $=10$
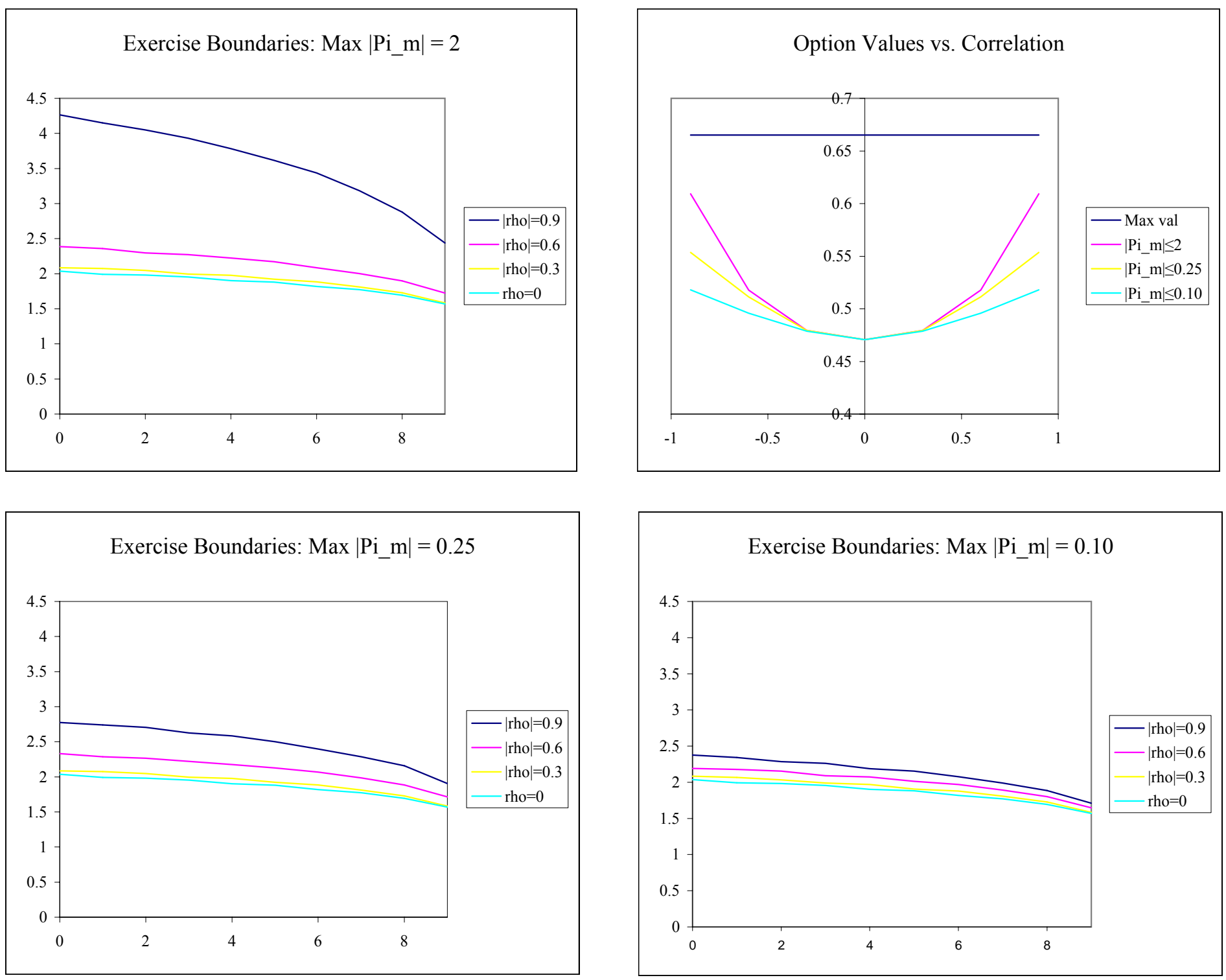
Figure 5 cont'd: Exercise Boundaries and Option Values for Various Levels of Correlation

b. Market risk premium $=0$, Initial wealth $=1.2$, Risk aversion $=2$
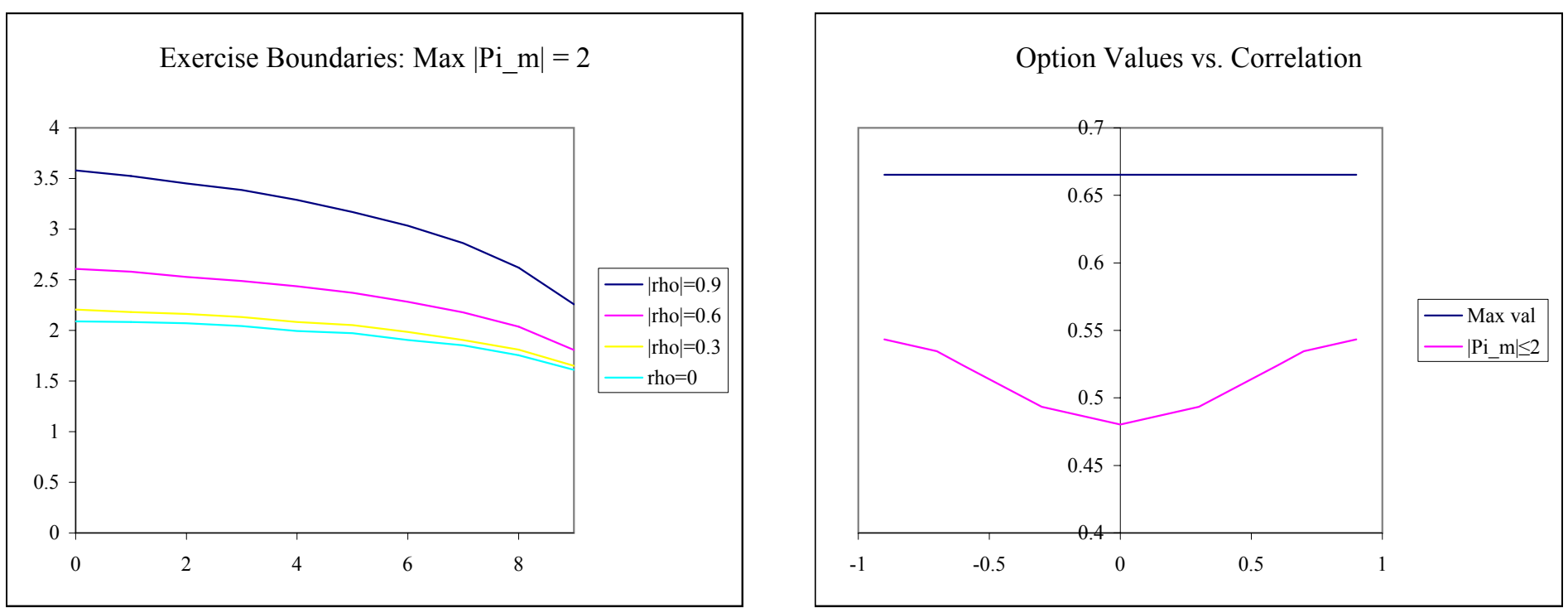

c. Market risk premium $=8 \%$
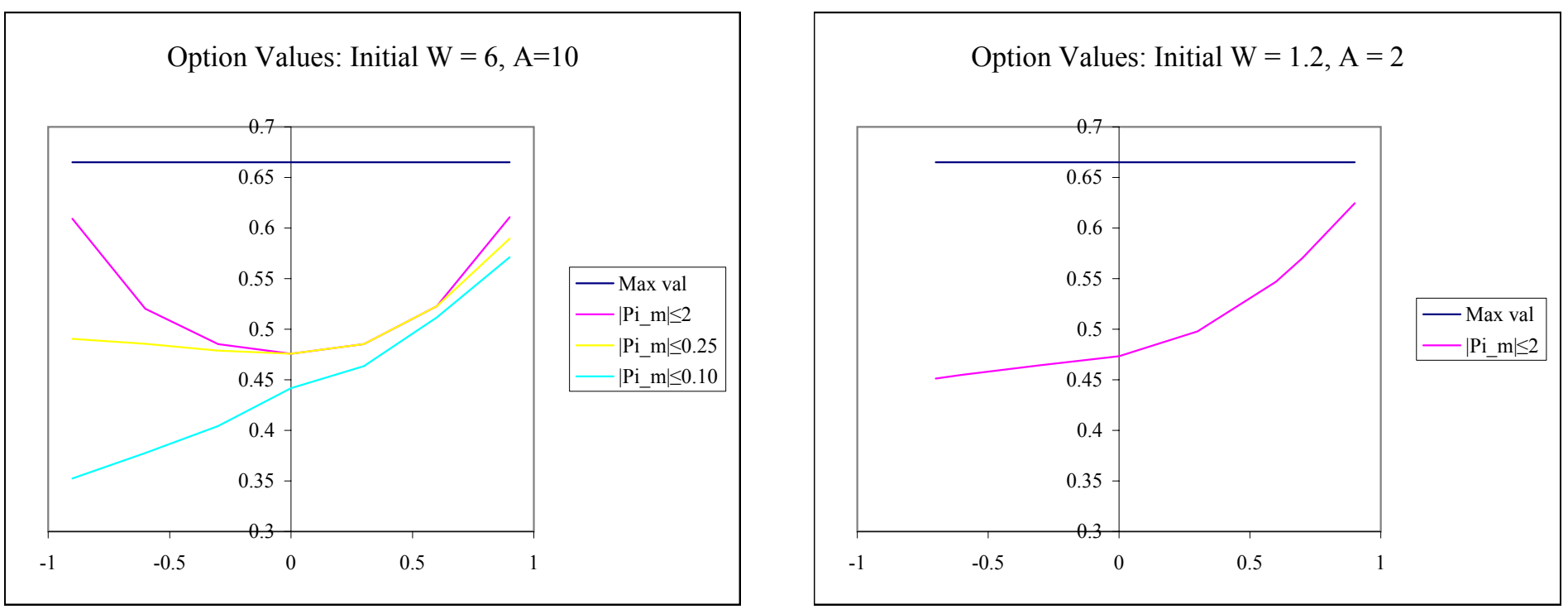
Figure 5 cont'd: Exercise Boundaries and Option Values for Various Levels of Correlation

d. Market risk premium $=-8 \%$

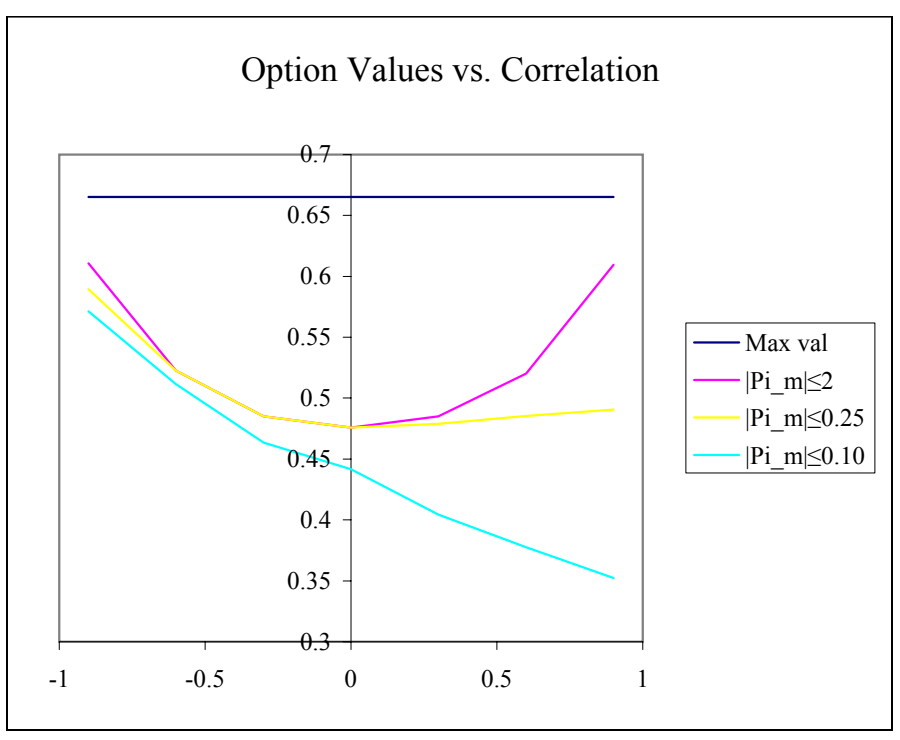

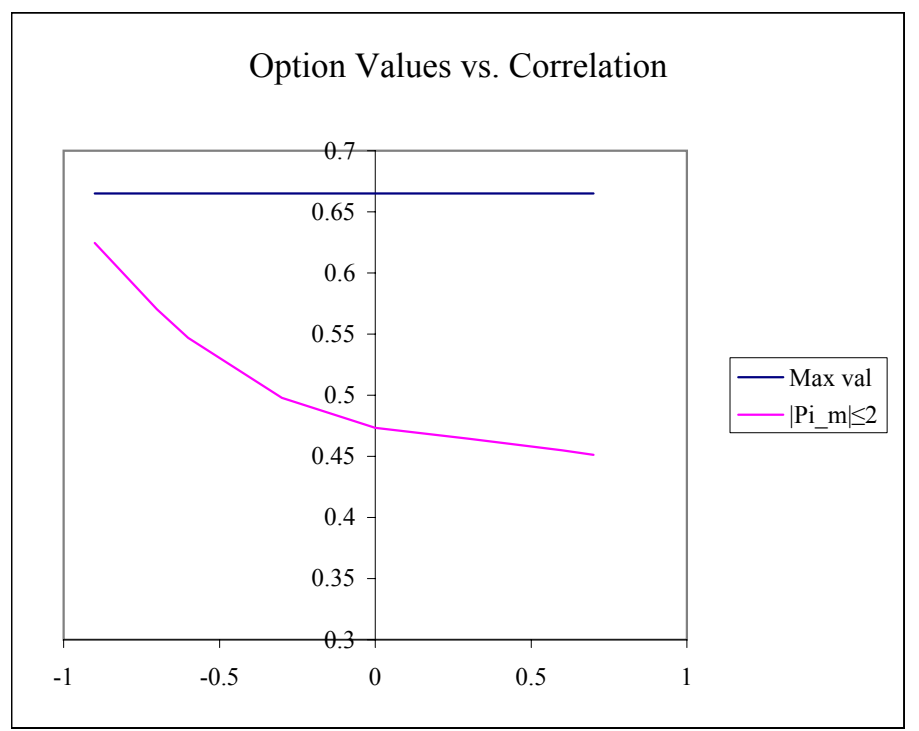


Table I

\section{Option Values and FASB Approximations}

Executive follows optimal option exercise policy and optimally invests outside wealth in market portfolio. Constant relative risk averse aversion coefficient is 4, outside wealth is 0.6 times value of underlying shares. Option vests in 2 years. Risk free rate is 5\%. Market portfolio return has mean $13 \%$ and volatility $20 \%$.

\begin{tabular}{|c|c|c|c|c|c|c|c|c|}
\hline \multirow[b]{2}{*}{ Changing } & \multicolumn{4}{|c|}{ Base Case 1: Vol=50\%, Div=0, Beta $=1.2$} & \multicolumn{4}{|c|}{ Base Case 2: $\mathrm{Vol}=30 \%$, Div $=3 \%$, Beta $=0.9$} \\
\hline & Expected & ESO & FASB & Approx & Expected & ESO & FASB & Approx \\
\hline & Term & Value & Approx & Error & Term & Value & Approx & Error \\
\hline
\end{tabular}

Panel A: Beta Effects

$\begin{array}{rrrrrrrrr}0.0 & 5.98 & 0.425 & 0.539 & 0.114 & 6.11 & 0.263 & 0.278 & 0.014 \\ 0.5 & 5.51 & 0.430 & 0.519 & 0.089 & 5.39 & 0.271 & 0.266 & -0.005 \\ 0.9 & 5.19 & 0.439 & 0.505 & 0.066 & 5.04 & 0.287 & 0.259 & -0.027 \\ 1.2 & 5.01 & 0.450 & 0.497 & 0.046 & 5.17 & 0.309 & 0.262 & -0.047 \\ 1.4 & 4.93 & 0.460 & 0.493 & 0.032 & 5.60 & 0.328 & 0.269 & -0.058\end{array}$

Panel B: Volatility Effects Holding Beta Constant

$\begin{array}{rrrrrrrrr}25 \% & 6.72 & 0.448 & 0.388 & -0.060 & 5.16 & 0.266 & 0.227 & -0.039 \\ 30 \% & 5.31 & 0.423 & 0.372 & -0.051 & 5.04 & 0.287 & 0.259 & -0.027 \\ 40 \% & 4.85 & 0.421 & 0.422 & 0.001 & 5.21 & 0.333 & 0.330 & -0.003 \\ 50 \% & 5.02 & 0.449 & 0.497 & 0.048 & 5.45 & 0.378 & 0.400 & 0.022 \\ 60 \% & 5.30 & 0.485 & 0.574 & 0.089 & 5.71 & 0.422 & 0.466 & 0.044\end{array}$

Panel C. Volatility Effects Holding Correlation Constant

$\begin{array}{rrrrrrrrr}25 \% & 5.12 & 0.339 & 0.330 & -0.010 & 5.16 & 0.257 & 0.227 & -0.030 \\ 30 \% & 4.97 & 0.359 & 0.358 & -0.001 & 5.04 & 0.287 & 0.259 & -0.027 \\ 40 \% & 4.93 & 0.404 & 0.425 & 0.022 & 5.04 & 0.345 & 0.327 & -0.019 \\ 50 \% & 5.01 & 0.450 & 0.497 & 0.046 & 5.10 & 0.397 & 0.392 & -0.005 \\ 60 \% & 5.17 & 0.493 & 0.568 & 0.075 & 5.21 & 0.444 & 0.455 & 0.011\end{array}$

Panel D: Dividend Rate Effects

$\begin{array}{rrrrrrrrr}0 \% & 5.01 & 0.450 & 0.497 & 0.046 & 4.94 & 0.376 & 0.357 & -0.019 \\ 3 \% & 5.24 & 0.387 & 0.395 & 0.008 & 5.04 & 0.287 & 0.259 & -0.027 \\ 10 \% & 5.85 & 0.271 & 0.209 & -0.062 & 5.70 & 0.156 & 0.105 & -0.051 \\ 50 \% & 9.08 & 0.024 & 0.000 & -0.024 & 9.78 & 0.002 & 0.000 & -0.002 \\ 90 \% & 9.93 & 0.001 & 0.000 & -0.001 & 10.00 & 0.000 & 0.000 & 0.000\end{array}$




\section{Table II}

\section{Subjective Option Values and Discount from Firm Cost}

Executive follows optimal option exercise policy and optimally invests outside wealth in market portfolio. Constant relative risk averse aversion coefficient is 4, outside wealth is 0.6 times value of underlying shares. Option vests in 2 years. Risk free rate is $5 \%$. Market portfolio return has mean $13 \%$ and volatility $20 \%$.

\begin{tabular}{|c|c|c|c|c|c|c|c|c|}
\hline \multirow[b]{2}{*}{ Changing } & \multicolumn{4}{|c|}{ Base Case 1: Vol=50\%, Div=0, Beta $=1.2$} & \multicolumn{4}{|c|}{ Base Case 2: $\mathrm{Vol}=30 \%$, Div $=3 \%$, Beta $=0.9$} \\
\hline & Sub & ESO & Max & Subj. & Subj. & ESO & Max & $\mathrm{Sul}$ \\
\hline & Value & Value & Value & Discount & Value & Value & Value & Disco \\
\hline
\end{tabular}

Panel A: Beta Effects

$\begin{array}{lllllllll}0.0 & 0.158 & 0.425 & 0.665 & 63 \% & 0.139 & 0.263 & 0.341 & 47 \% \\ 0.5 & 0.167 & 0.430 & 0.665 & 61 \% & 0.151 & 0.271 & 0.341 & 44 \% \\ 0.9 & 0.180 & 0.439 & 0.665 & 59 \% & 0.179 & 0.287 & 0.341 & 37 \% \\ 1.2 & 0.197 & 0.450 & 0.665 & 56 \% & 0.224 & 0.309 & 0.341 & 28 \% \\ 1.4 & 0.212 & 0.460 & 0.665 & 54 \% & 0.279 & 0.328 & 0.341 & 15 \%\end{array}$

Panel B: Volatility Effects Holding Beta Constant

$\begin{array}{lllllllll}25 \% & 0.400 & 0.448 & 0.488 & 11 \% & 0.190 & 0.266 & 0.298 & 29 \% \\ 30 \% & 0.297 & 0.423 & 0.526 & 30 \% & 0.179 & 0.287 & 0.341 & 37 \% \\ 40 \% & 0.231 & 0.421 & 0.602 & 45 \% & 0.165 & 0.333 & 0.425 & 50 \% \\ 50 \% & 0.197 & 0.450 & 0.665 & 56 \% & 0.153 & 0.378 & 0.502 & 60 \% \\ 60 \% & 0.171 & 0.485 & 0.737 & 65 \% & 0.140 & 0.422 & 0.571 & 67 \%\end{array}$

Panel C. Volatility Effects Holding Correlation Constant

$\begin{array}{lllllllll}25 \% & 0.214 & 0.339 & 0.488 & 37 \% & 0.171 & 0.257 & 0.298 & 33 \% \\ 30 \% & 0.212 & 0.359 & 0.526 & 41 \% & 0.179 & 0.287 & 0.341 & 37 \% \\ 40 \% & 0.206 & 0.404 & 0.602 & 49 \% & 0.188 & 0.345 & 0.425 & 46 \% \\ 50 \% & 0.197 & 0.450 & 0.665 & 56 \% & 0.187 & 0.397 & 0.502 & 53 \% \\ 60 \% & 0.182 & 0.493 & 0.737 & 63 \% & 0.180 & 0.444 & 0.571 & 60 \%\end{array}$

Panel D. Dividend rate effects

$\begin{array}{rrrrrrrrr}0 \% & 0.197 & 0.450 & 0.665 & 56 \% & 0.233 & 0.376 & 0.524 & 38 \% \\ 3 \% & 0.168 & 0.387 & 0.503 & 57 \% & 0.179 & 0.287 & 0.341 & 37 \% \\ 10 \% & 0.117 & 0.271 & 0.309 & 57 \% & 0.097 & 0.156 & 0.165 & 38 \% \\ 50 \% & 0.011 & 0.024 & 0.024 & 53 \% & 0.001 & 0.002 & 0.002 & 29 \% \\ 90 \% & 0.000 & 0.001 & 0.001 & 44 \% & 0.000 & 0.000 & 0.000 & 17 \%\end{array}$

